\title{
Contribuições aos estudos toponímicos da Libras através da análise de sinais que designam cidades brasileiras
}

\section{Contributions to Libras toponymic studies through the analysis of toponyms that designate Brazilian cities in Libras}

\author{
Ítalo Rullian Webster URBANSKI* \\ Daiane FERREIRA** \\ André Nogueira XAVIER ${ }^{* * *}$
}

\begin{abstract}
RESUMO: Topônimos são palavras que nomeiam lugares e acidentes geográficos (DICK, 1990). Este trabalho apresenta resultados da análise de 888 topônimos da Libras que designam cidades de 14 estados brasileiros e regiões administrativas do DF. Os dados foram coletados no Youtube e as informações sobre sua origem, ou seja, se formados sem influência do português (nativos) ou por meio de empréstimos dessa língua, foram registradas em um banco de dados criado no programa Access do pacote Office da Microsoft. Nesse banco, foram registrados também, no caso dos empréstimos, os tipos de processos que os constituíram, a saber, (1) calque (tradução literal ou aproximada), (2) inicialização, (3) combinação de letra(s) do alfabeto manual da Libras que remetem à(s) letra(s) inicial(is) do topônimo escrito em português com

ABSTRACT: Toponyms are words that name places and geographical accidents (DICK, 1990). This paper reports results of the analysis of 888 Libras toponyms designating cities in 14 Brazilian states and administrative regions of the Federal District. The data were collected on Youtube and information on their origin, that is, whether they were created without influence from Portuguese (native signs) or by means of borrowing from that language, was recorded in a database created in the Microsoft Office Access program. In this database, the types of processes that formed those loan signs were also recorded, that is, whether they were created as a result of (1) literal translation, (2) initialization, (3) a combination of Libras manual alphabet letters that refer to the initial letter(s) of the written Portuguese toponym with other Libras phonological parameters and
\end{abstract}

\footnotetext{
Graduando em licenciatura em Letras Libras pela Universidade Federal do Paraná. ORCID: https://orcid.org/0000-0003-0768-0670. italokuk@gmail.com.

** Mestre em Tradução pela Universidade Federal de Santa Catarina. ORCID: https://orcid.org/00000002-6294-2453. daiatmaufpr@gmail.com.

** Doutor em linguística pela Universidade Estadual de Campinas, professor do curso de licenciatura em Letras Libras da UFPR. ORCID: $\underline{\text { https://orcid.org/0000-0002-8464-1977. andrexavier@ufpr.br. }}$
} 
outros parâmetros fonológicos da Libras e (4) soletração manual. Os resultados indicam que os topônimos analisados, em sua maioria, são empréstimos do português e que estes, mais frequentemente, são formados por meio do terceiro processo.

PALAVRAS-CHAVE: Topônimos. Empréstimos. Cidades Brasileiras. Libras.
(4) fingerspelling. The results indicate that the toponyms analyzed are mostly borrowings from Portuguese and that these, more often, are formed through the third process.

\section{Introdução}

O Brasil é formado por 26 estados mais o Distrito Federal. O nome desses estados e de seus municípios é designado no âmbito dos estudos linguísticos como topônimos (do grego: topo- (lugar), -ônimo (nome)). Eles podem ter sua origem no português (e.g.: Dois Vizinhos) ou em outras línguas, com destaque, no caso da toponímia brasileira, para as indígenas (e.g.: Curitiba). Há ainda casos de hibridismo, ou seja, de topônimos formados através da composição de elementos de línguas diferentes (e.g.: Piraí do Sul: Piraí (tupi: pira- (peixe), -í (rio); Sul (português)).

Este trabalho objetiva analisar topônimos da Libras que designam municípios brasileiros e regiões administrativas do Distrito Federal. Como embasamento, na seção 2, apresentamos uma síntese de trabalhos sobre topônimos na Libras. Na seção 3, descrevemos nosso método de coleta e análise de dados. Por fim, na seção 4, reportamos nossos resultados e, na seção 5, apresentamos nossas considerações finais.

\section{Pressupostos teóricos e revisão de literatura}

De acordo com Dick (1990), a palavra toponímia "(do gr. topos, "lugar" e onoma, "nome")" se refere ao "estudo dos nomes de lugares ou dos designativos geográficos, em sua bipartimentação física (rios, córregos, morros, etc.) e humana, 
antrópica, ou cultural (aldeias, povoados, cidades, etc.)". A autora define como objetivos dessa disciplina:

a - estudo da natureza linguística dos topônimos que conformam a nomenclatura geográfica brasileira, provenientes das camadas linguísticas intercorrentes: a indígena, distribuída em suas diversas famílias; a portuguesa (ou brasileira propriamente dita); a africana; nomes de origem estrangeira, de filiação mais recente; análise dos fenômenos de linguagens pertinentes;

b - estudo da motivação ou da natureza semântica dos nomes envolvidos no ordenamento onomástico brasileiro, de modo a se configurar as tipologias dominantes, segundo áreas específicas de ocorrências (DICK, 1990b, p. 46, grifos nossos).

Em relação à natureza linguística, com base em dados da toponímia brasileira, ela propõe três categorias morfológicas para os signos toponímicos.

1. Topônimo ou elemento específico simples: definido por apenas um formante (adjetivo, substantivo), podendo estar acompanhado de sufixos aumentativos ou diminutivos: Alminhas (Cachoeira do Sul, $\mathrm{RS})$.

2. Topônimo composto ou elemento específico composto: apresenta mais de um elemento formador, de origem de conteúdo diversa e às vezes constituem formações inusitadas: Lava Roupa (Ribeirão, GO). Elementos de origem tupi estão presentes na formação de variados compostos: - guaçu (grande); -mirim (pequeno).

3. Topônimo híbrido ou elemento específico híbrido: possui elementos linguísticos de variadas procedências, sendo mais frequentes no Brasil a indígena + portuguesa ou a portuguesa + indígena: Mirante do Paranapanema (AH4, SP) (DICK, 1990b, p. 12$14)$.

Já em relação à motivação ou natureza semântica, a autora propõe duas grandes categorias de taxes: uma para reunir topônimos que se referem à natureza física e outra para agrupar taxes de natureza antropocultural (DICK, 1990).

$\mathrm{Na}$ primeira categoria, Dick inclui os astrotopônimos (Ex.: Estrela (BA), cardinotopônimos (Ex.: Juazeiro do Norte (CE)), cromotopônimos (Ex.: Rio Negro 
(PR)), dimensiotopônimos (Ex.: Igarapé Profundo (RO)), fitotopônimos (Ex: Palmital (SP)), geomorfotopônimos (Ex.: Colinas do Tocantins (TO)), hidrotopônimos (Ex.: Cachoeira (BA)), litotopônimos (Ex.: Areial (PB)), meteorotopônimos (Ex.: Primavera (PE)), morfotopônimos (Ex.: Ilha Quadrada (RS)) e zootopônimos (Ex.: Galinhos $(\mathrm{RN}))$.

Já na segunda categoria, ela reúne os animotopônimos ou nootopônimos (Ex.: Almas (TO)), antropotopônimos (Ex.: Antônio Carlos (SC)), axiotopônimos (Ex.: Presidente Figueiredo (AM)), corotopônimos (Ex.: Filadélfia (BA)), cronotopônimos (Ex.: Nova Andradina (MS)), ecotopônimos (Casa Nova (BA)), ergotopônimos (Ex.: Relógio (PR)) etnotopônimos (Ex.: Xambioá (TO)), dirrematotopônimos (Ex.: Há Mais Tempo (MA)) e hierotopônimos (Ex.: Natividade (TO)) - estes se subdividem em hagiotopônimos (Ex.: Santa Luzia (MG)) e mitotopônimos (Ex.: Anhagá (BA)) -, historiotopônimos: (Ex.: $1^{\text {o }}$ de Maio (PR)), hodotopônimos (odotopônimos) (Ex.: Estradas (AM)), numerotopônimos (Ex.: Dois Irmãos do Buriti (MS)) poliotopônimos (Ex.: Aldeias Altas (MA)), sociotopônimos (Ex.: Pescador (MG)) e somatotopônimos (Ex.: Pé de Galinha (BA)).

Os estudos toponímicos da Libras são recentes e ainda muito incipientes. Os primeiros datam de 2012 e foram desenvolvidos por Souza-Júnior (2012) e Aguiar (2012). De acordo com Souza-Júnior, os topônimos na Libras também se conformam às categorias morfológicas propostas por Dick (1990). Conforme se pode ver na Figura 1, há nessa língua topônimos formados por um único sinal (cf. FLORIANÓPOLIS (SC)), formados por mais de um sinal (cf. PAU-DOS-FERROS (RN)) e híbridos (RIODE-JANEIRO (RJ)). 
Figura 1 - Exemplos de tipos de topônimos da Libras.

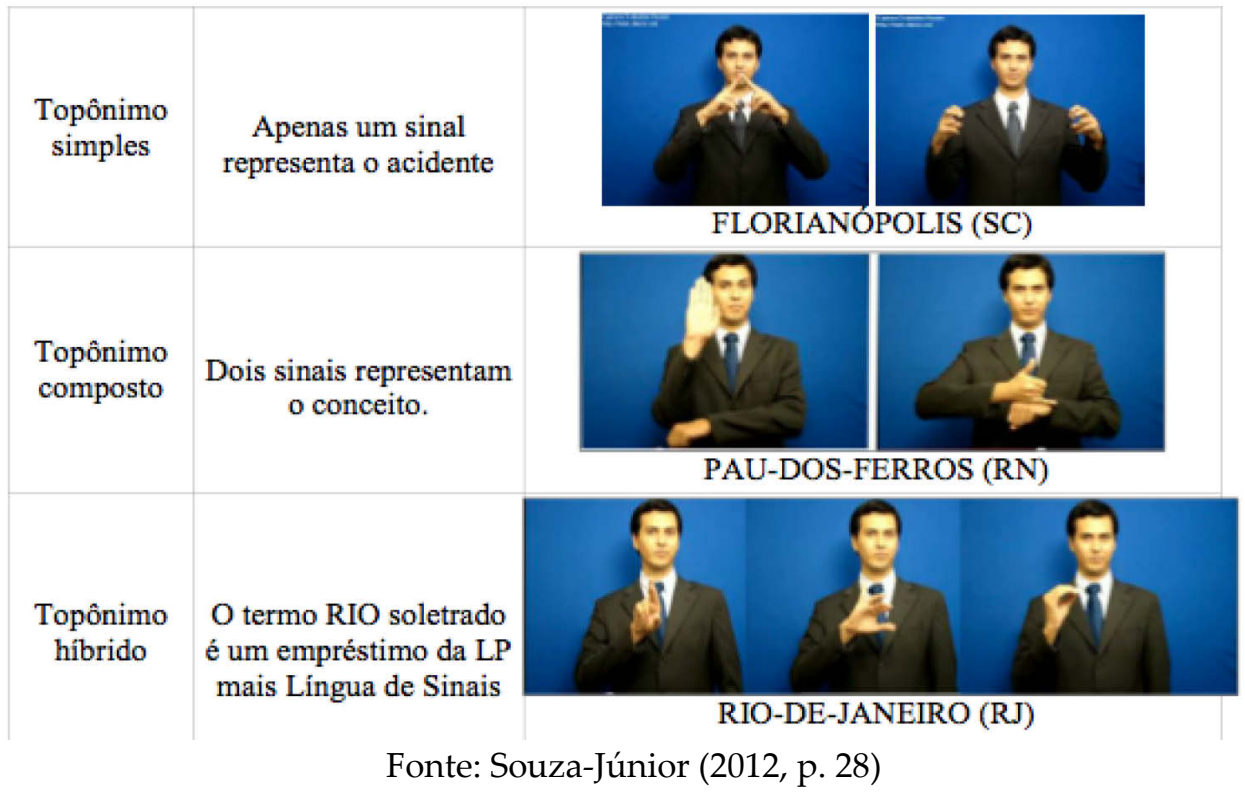

Souza-Júnior (2012) coletou 265 topônimos que incluem sinais para estados da Federação, suas capitais e algumas cidades interioranas. Esses dados foram obtidos de 20 informantes residentes nas regiões pesquisadas e armazenados e validados através de um $b \log ^{1}$.

O referido autor classificou os topônimos coletados com base nas taxes propostas por Dick. Em razão de a maior parte deles não se encaixar em nenhuma das subcategorias das taxes de natureza física ou antropocultural propostas pela autora, Souza-Júnior propôs a categoria grafotopônimo (Figura 3a). De acordo com ele, encaixam-se nesse grupo sinais toponímicos como SÃO-PAULO (Figura 3b), cuja configuração de mão remete à letra 'p', portanto "motivad[a] pela grafia do nome original do lugar, ou acidente geográfico" (p. 60).

\footnotetext{
${ }^{1}$ http://geografiaemlibras.blogspot.com/
} 
Figura 2 - Resultados obtidos por Souza-Júnior (2012) (a) e exemplo de grafotopônimo (b).

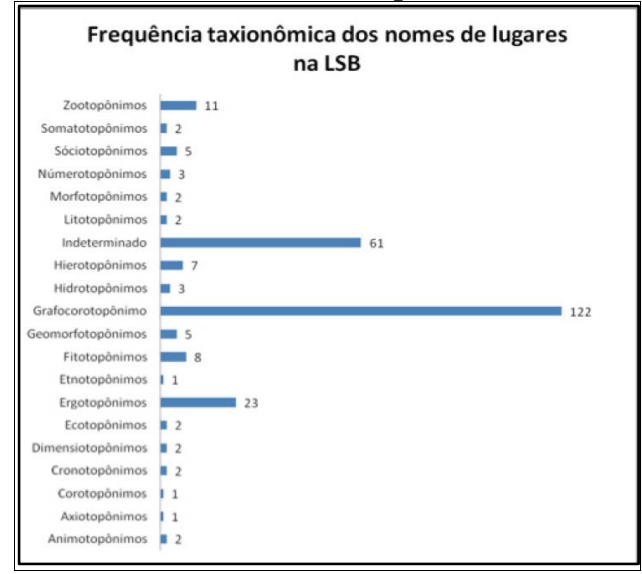

(a)

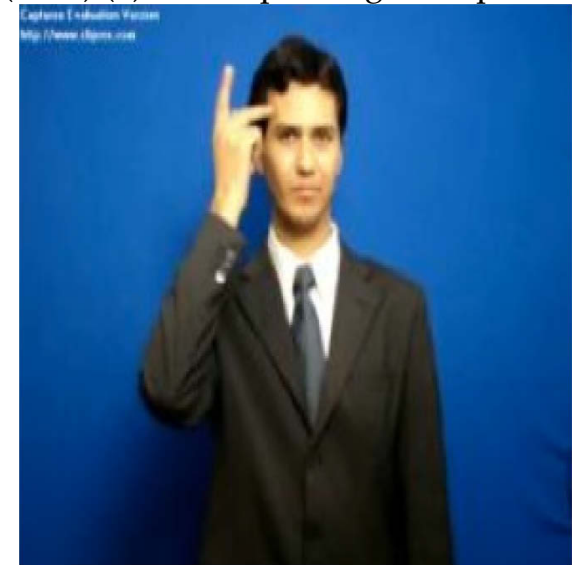

(b)

Fonte: Souza-Júnior (2012, p. 57 e p. 324).

Um estudo semelhante foi realizado por Aguiar (2012), que examinou 252 topônimos coletados do Novo Dicionário Enciclopédico Ilustrado Trilíngue de Libras (CAPOVILLA; RAPHAEL; MAURÍCIO, 2009). Os dados analisados pela autora compreenderam sinais que designam continentes, ilhas, países, regiões, estados e cidades brasileiros, bem como bairros da cidade de São Paulo. Seus dois principais critérios de análise foram a iconicidade e a origem. Por meio deles, ela diferenciou sinais como AMÉRICA (Figura 3a), cuja forma não parece ser influenciada pelo português, de sinais oriundos de empréstimos dessa língua, como BRASIL (Figura 3b).

Figura 3 - Exemplo de topônimo icônico (a) e de topônimo oriundo de empréstimo do português

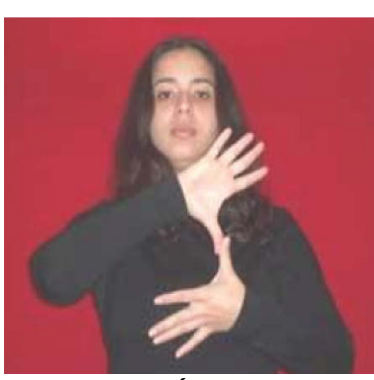

AMÉRICA

(a)

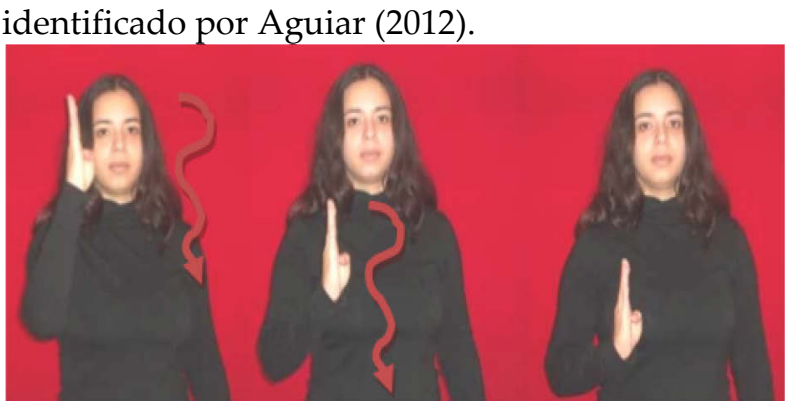

BRASIL

(b)

Fonte: Aguiar (2012, p. 112 e p. 116). 
A autora obteve resultados semelhantes aos de Souza-Júnior (2012). Como mostra o gráfico em (4), em seus dados, predominam sinais, em seus termos, nãoicônicos, ou seja, resultantes de empréstimos do português.

Figura 4 - Resultados obtidos por Aguiar (2012).

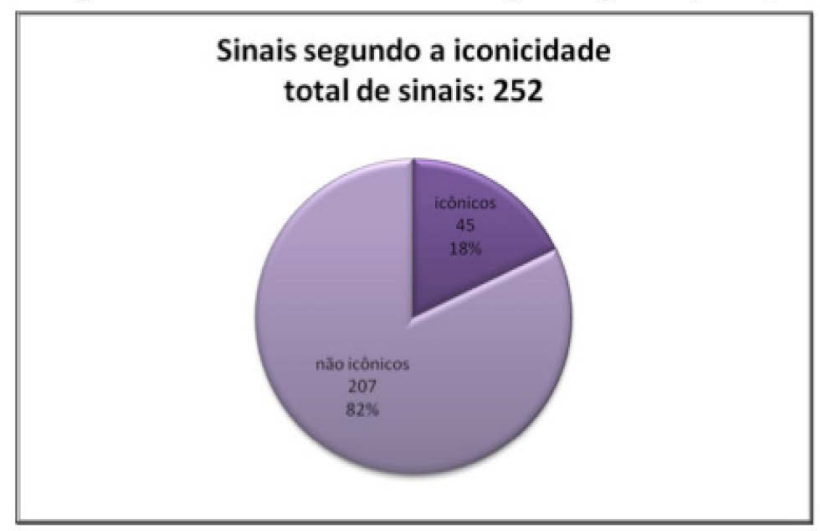

Fonte: Aguiar (2012, p. 118).

Mais recentemente, vêm sendo realizados, ainda que em estágios iniciais, estudos sobre topônimos em Libras de outras partes do Brasil, a saber, do Sergipe (NUNES, 2018), da Bahia (JESUS, 2019; FERREIRA, 2019), do Rio de Janeiro (CAMPELO; LESSER, 2019), do Pará (CHAVES; LOBATO; SILVA, 2019), de Goiás (SOUZA; NOVODVORSKI, 2020; CHAIBUE, em preparação) e do Tocantins (MIRANDA, 2020). Além desses, podemos citar também o trabalho de Sousa e Quadros (2019a, 2019b) que vem documentando, descrevendo e analisando topônimos em Libras do Acre. Os referidos autores investigaram aspectos formais e motivacionais dos sinais que nomeiam os 22 municípios acreanos e, semelhantemente a Souza-Junior, classificaram-nos com base nas taxes propostas por Dick (1990). Para acomodar a maior parte dos sinais em análise, no entanto, eles recorreram à categoria acronimotopônimos proposta por Francisquini (1998) apud Sousa e Quadros (2019a) justamente para abrigar topônimos formados por siglas ou letras do alfabeto. $\mathrm{O}$ Quadro 1, reproduzido e adaptado de Sousa e Quadros (2019a), interessantemente, mostra não apenas que a maioria dos sinais que designam os municípios acreanos é 
formada por empréstimos do português (59\%) e é do tipo acronimotopônimos, mas também que os topônimos considerados diferem marcadamente dos topônimos correspondentes em língua portuguesa do ponto de vista de suas motivações.

Quadro 1 - Topônimos em português e em Libras classificados segundo Dick (1990).

\begin{tabular}{|c|c|c|}
\hline ESPAÇO GEOGRÁFICO & $\begin{array}{l}\text { TAXIONOMIA EM } \\
\text { PORTUGUÊS }\end{array}$ & $\begin{array}{c}\text { TAXIONOMIA EM } \\
\text { LIBRAS }\end{array}$ \\
\hline Acrelândia & Corotopônimo & \multirow{13}{*}{ Acronimotopônimo } \\
\hline Bujari & Etnotopônimo & \\
\hline Epitaciolândia & Antropotopônimo & \\
\hline Mancio Lima & Antropotopônimo & \\
\hline Manoel Urbano & Antropotopônimo & \\
\hline Marechal Thaumaturgo & Axiotopônimo & \\
\hline Porto Acre & Sociotopônimo & \\
\hline Porto Walter & Sociotopônimo & \\
\hline Rodrigues Alves & Antropotopônimo & \\
\hline Santa Rosa do Purus & Hierotopônimo & \\
\hline Sena Madureira & Antropotopônimo & \\
\hline Senador Guiomard & Axiotopônimo & \\
\hline Tarauacá & Hidrotopônimo & \\
\hline Rio Branco & Historiotopônimo & Cromotopônimo \\
\hline Capixaba & Etnotopônimo & Dimensiotopônimo \\
\hline Jordão & Hidrotopônimo & Ergotopônimo \\
\hline Plácido de Castro & Historiotopônimo & Ergotopônimo \\
\hline Assis Brasil & Antropotopônimo & Geomorfotopônimo \\
\hline Cruzeiro do Sul & Astrotopônimo & Hagiotopônimo \\
\hline Brasiléia & Corotopônimo & Hodotopônimo \\
\hline
\end{tabular}




\begin{tabular}{|c|c|c|}
\hline Feijó & Antropotopônimo & Sociotopônimo \\
\hline Xapuri & Etnotopônimo & Sociotopônimo \\
\hline
\end{tabular}

Fonte: reproduzido e adaptado de Sousa e Quadros (2019a, p. 71).

Um dos desdobramentos do trabalho de Sousa e Quadros (2019a) é o Websoftware Toponímia em Libras². Conforme descrevem Souza e Quadros (2019b), esse site serve tanto como um repositório dos topônimos acreanos em Libras, quanto como uma fonte de informações sobre sua etimologia/constituição e sua escrita em Sign Writing.

Figura 5 - Websoftware Toponímia em Libras.

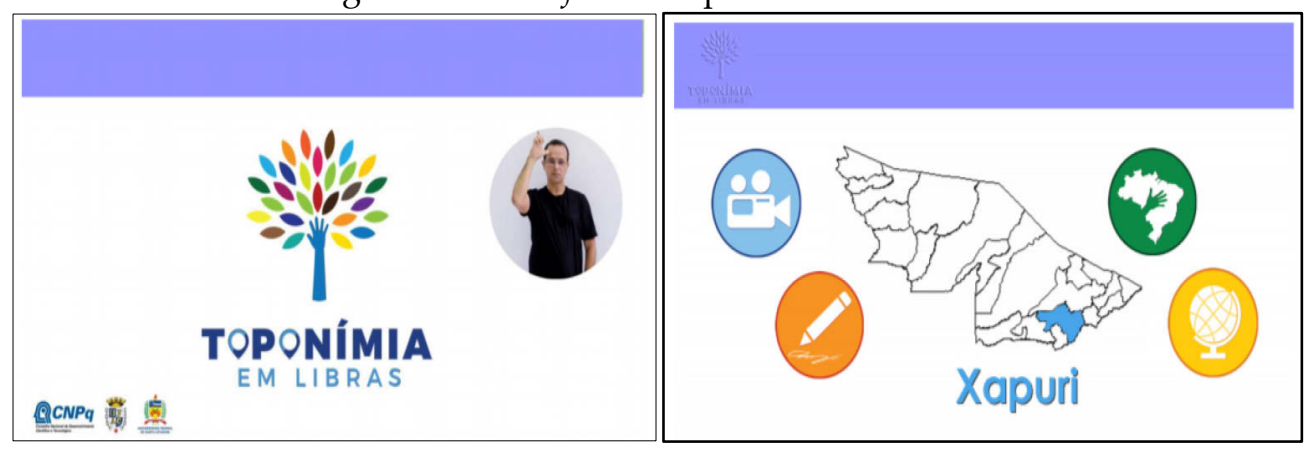

Fonte: Sousa (2019b, p. 28-29).

No Paraná, Urbanski, Xavier e Ferreira (2019) documentaram e analisaram sinais que designam 64 dos 399 municípios desse estado. Os autores classificaram tais sinais como nativos, formados sem aparente influência do português, ou empréstimos do português e, neste último caso, os subclassificaram como calques (traduções literais ou aproximadas), derivados de soletrações manuais, inicializações (casos em que um sinal nativo teve sua configuração de mão original substituída por uma das que compõem o alfabeto manual e faz referência à letra inicial do topônimo escrito em

\footnotetext{
${ }^{2}$ http://www.toponimialibras.com/
} 
português (ADAM, 2012)), ou hibridismo3 ${ }^{3}$, isto é, sinais formados através da combinação de letras do alfabeto manual e outros parâmetros fonológicos da Libras (Figura 6).

Figura 6 - Critérios de classificação de Urbanski, Xavier e Ferreira (2019).

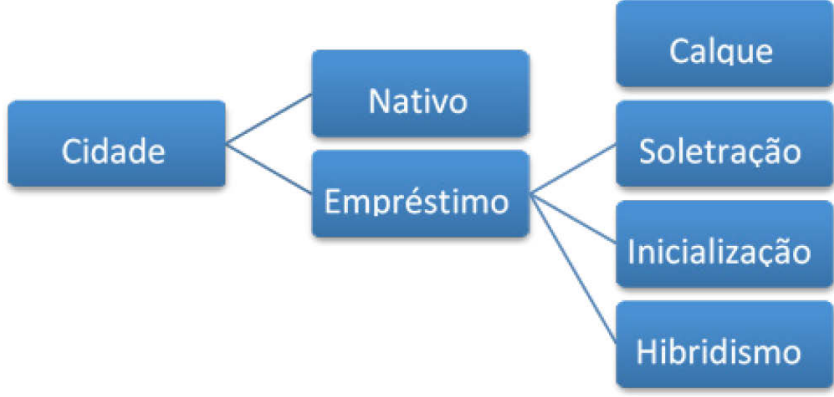

Fonte: Urbanski, Xavier e Ferreira (2019, p. 68).

Entre os topônimos coletados e analisados, Urbanski, Xavier e Ferreira observaram tanto sinais que, como o do município Castro (Figura 7a), não apresentam nenhuma relação aparente com o português, quanto como o de Londrina (Figura 7b), que constituem casos de empréstimo do português, uma vez que, nesse caso específico, o sinal é formado, segundo os autores, por meio da combinação da configuração de mão que, no alfabeto manual, representa a inicial do topônimo em português, com outros parâmetros fonológicos da Libras.

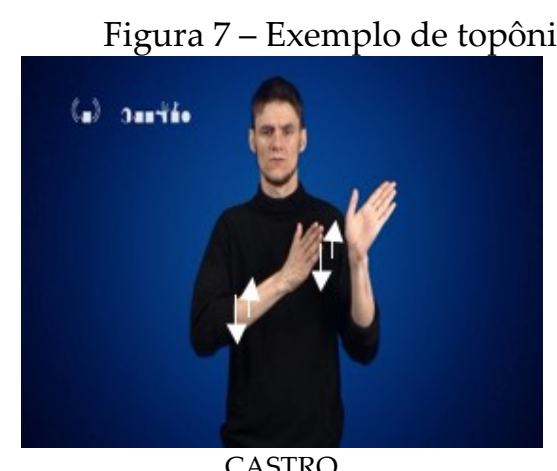

(a)

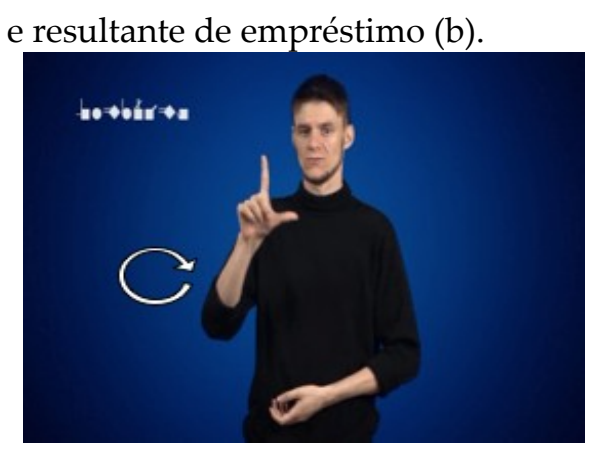

LONDRINA

(b)

Fonte: Urbanski, Xavier e Ferreira (2019, p. 70)

\footnotetext{
${ }^{3}$ Como se verá mais adiante, neste trabalho, optamos por designar esses casos como "formados a partir de letras", tendo em vista que, de certo modo, as outras subcategorias de empréstimos também podem ser vistas como híbridas.
} 
Semelhantemente a Souza-Júnior (2012) e Aguiar (2012), os dados coletados pelos referidos autores indicam uma maior frequência de topônimos formados a partir de empréstimos do português. Dentre estes, Urbanski, Xavier e Ferreira observaram não apenas casos como LONDRINA, em sua tipologia, denominados híbridos, mas também calques como PATO-BRANCO (Figura 8a), sinais derivados de soletrações, como CORNÉLIO-PROCÓPIO ${ }^{4}$ (Figura 8b) e de inicializações, como IRATI $^{5}$ (Figura 8c).

Figura 8 - Exemplos de topônimos resultante de tradução literal (calque) (a), formado a partir de soletração manual (b) e de inicialização (c).

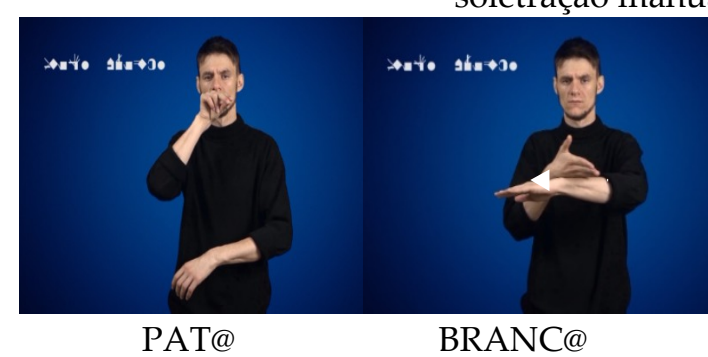

Pato Branco

(a)

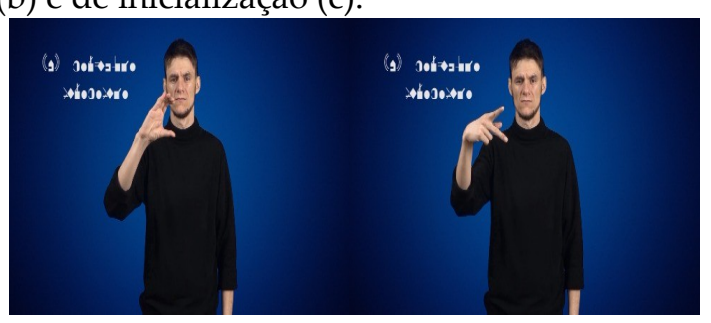

C Cornélio Procópio

(b)

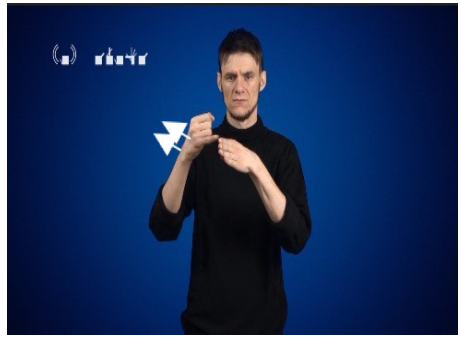

IRATI

(c)

Fonte: Urbanski, Xavier e Ferreira (2019, p. 71).

Conforme indica o gráfico em (9), os topônimos formados por hibridismo foram os mais frequentes. Os calques ficaram em segundo lugar e os formados por soletração e inicialização empataram em terceiro com apenas um caso atestado. A categoria

\footnotetext{
${ }^{4}$ Este sinal foi analisado como um caso de soletração, porque, diferentemente de LONDRINA, é realizado com o movimento tipicamente observado quando palavras são manualmente soletradas, o qual pode resultar unicamente da mudança de configuração ou do deslocamento lateral da mão.

${ }^{5}$ Este sinal foi analisado como um caso de inicialização, porque ele parece derivar do sinal FÓSFORO, provavelmente empregado para se referir à cidade, em razão de haver aí uma antiga fábrica de fósforos.
} 
'outro' se refere a topônimos cuja subcategoria não pôde ser determinada pelos autores.

Figura 9 - Frequência dos diferentes tipos de empréstimos.

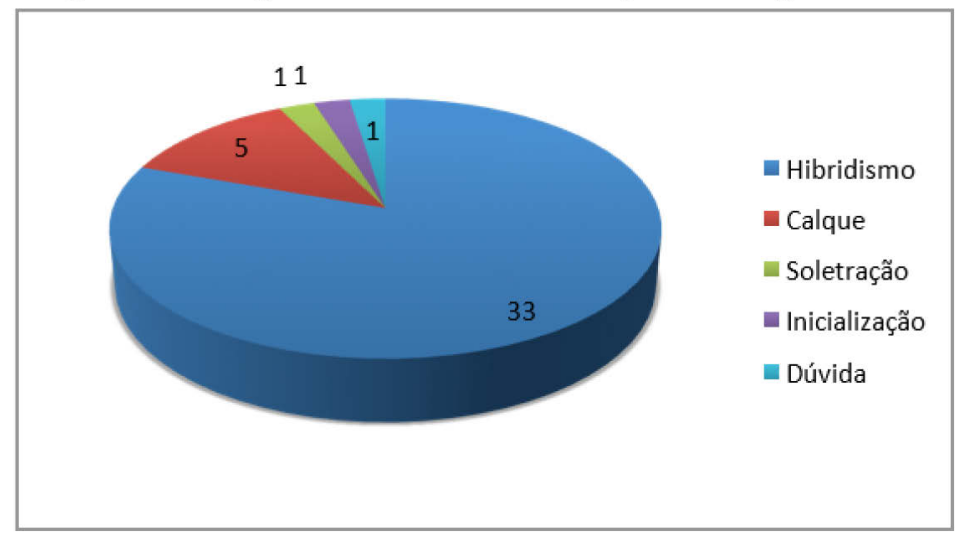

Fonte: Urbanski, Xavier e Ferreira (2019, p. 72).

Urbanski, Xavier e Ferreira ainda registram que para oito cidades foram observadas variantes fonológicas e para três, variantes lexicais. As variantes de PONTA-GROSSA ilustram os dois casos. Como mostram as imagens na Figura 10a-b, foram documentadas duas formas para a cidade Ponta Grossa que diferem unicamente na configuração de mão, representando, portanto, variantes fonológicas. Contrastam com estas, a forma mostrada na Figura 10c que por diferir totalmente das duas anteriores, constitui um caso de variação lexical ${ }^{6}$. Assim como no caso de outras variantes lexicais, os participantes da sessão de coleta descreveram a forma em 10c como arcaica. Embora os autores tenham reportado essa informação, dado o estágio muito incipiente de seu estudo, consideraram prematuro dizer se essas variantes deixaram ou não de ser usadas.

\footnotetext{
${ }^{6}$ Esta variante parece ser um caso de calque do português fazer referência a um objeto com ponta grossa.
} 
Figura 10 - Exemplos de variantes fonológicas ((a) e (b)) e lexicais ((a)/(b) e (c)) para referir-se à cidade Ponta Grossa.

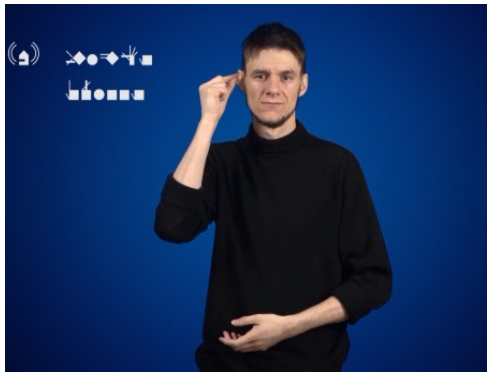

(a)

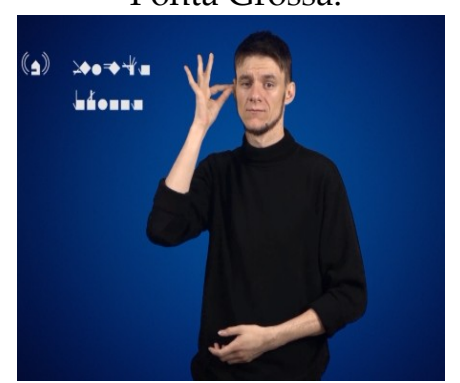

(b)

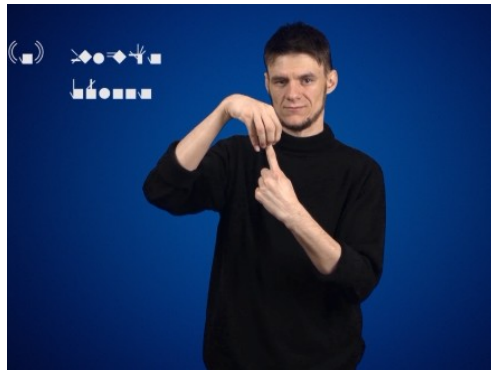

(c)

Fonte: Urbanski, Xavier e Ferreira (2019, p. 72-3).

Resultados semelhantes foram obtidos em um estudo que focou nos topônimos referentes a bairros da cidade de Curitiba-PR (FERREIRA; XAVIER, 2019). Dos 75 bairros, os autores coletaram sinais para 37. Dentre estes, observaram a ocorrência tanto de sinais nativos, ou seja, formados sem a influência do português, quanto de empréstimos dessa língua.

Um exemplo do primeiro tipo é o sinal que nomeia o bairro Jardim Botânico (Figura 11a), cuja forma remete à estufa. Já um exemplo do segundo é o sinal que designa o bairro Campo do Siqueira (Figura 11b), formado a partir das letras do alfabeto manual C e S, iniciais de cada parte do topônimo em português.

Figura 11 - Sinais que designam bairros de Curitiba: (a) nativo e (b) empréstimo.

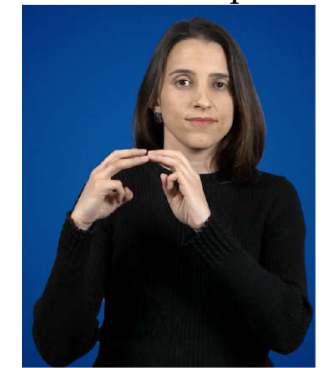

JARDIM-BOTÂNICO

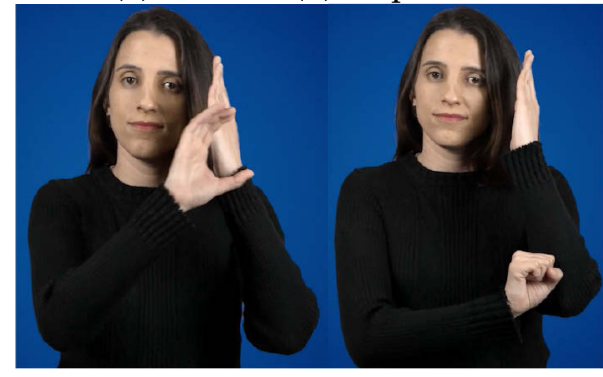

CAMPO-SIQUEIRA

(b)

Fonte: Ferreira e Xavier (2019, p. 13). 
Conforme mostra o gráfico na Figura 12a, os empréstimos também são mais frequentes nos dados e, entre estes, predominam os hibridismos e os calques, ou seja, traduções literais para a Libras de topônimos em português (Figura 12b).

Figura 12 - Resultados do estudo de Ferreira e Xavier (2019).

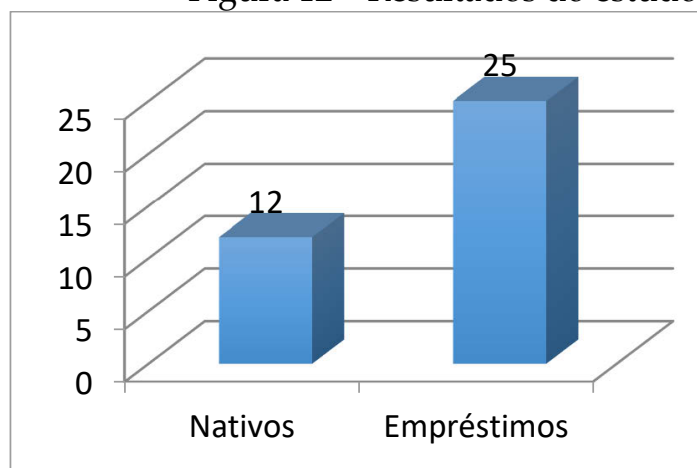

(a)

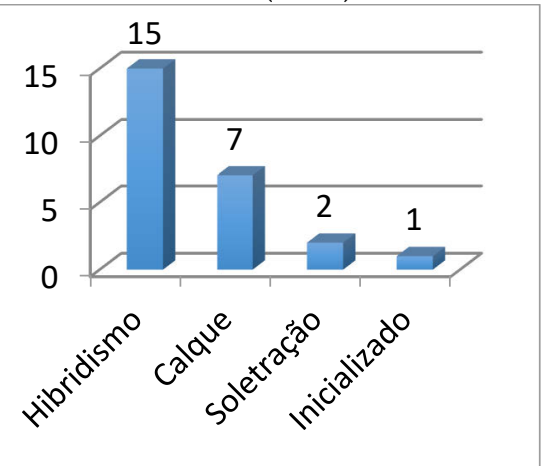

(b)

Fonte: Ferreira e Xavier (2019, p. 14).

Como exemplificação dos diferentes tipos de empréstimos, isto é, de hibridismos, calques, soletração e inicializados entre os sinais que nomeiam bairros curitibanos, Ferreira e Xavier citam, respectivamente, os sinais CAMPINA-DOSIQUEIRA (Figura 11b), NOVO-MUNDO (Figura 13a), SÃO-FRANCISCO (Figura 13b), e BATEL 7 (Figura 13c).

Figura 13 - Exemplos de tipos de empréstimo: (a) calque, (b) soletração e (c) inicialização.

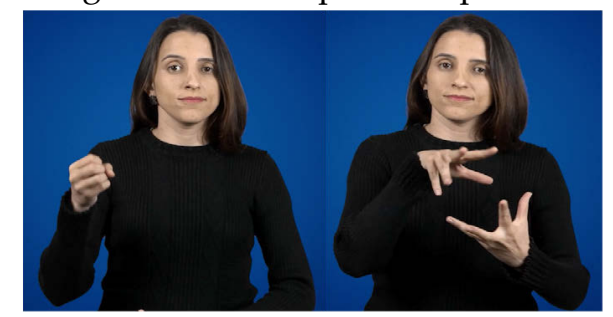

NOV@

$$
\text { MUNDO }
$$

(a)

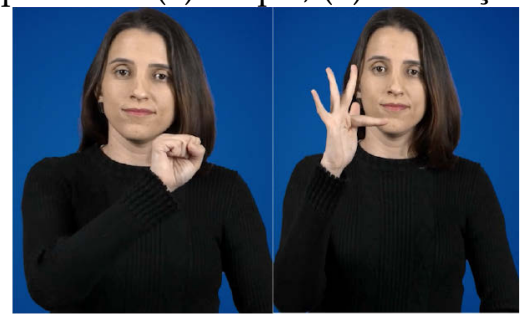

$S$ SÃO-FRANCISCO

(b)

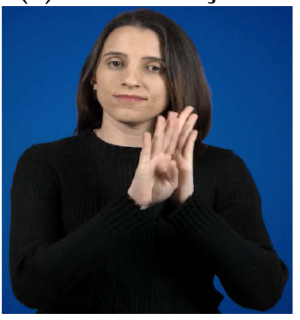

BATEL

(c)

Fonte: Ferreira e Xavier (2019, p. 14).

\footnotetext{
${ }^{7} \mathrm{O}$ sinal foi analisado como resultante de um processo de inicialização em virtude de parecer derivar do sinal IGREJA-BATISTA que, na mão ativa, apresenta a configuração em A.
} 
Com base nos estudos sobre topônimos paranaenses, sinais de cidades e bairros de Curitiba, pode-se dizer que estes, como sugere o continuum do Quadro 2, se manifestam através de formas que vão desde as nativas, ou seja, criadas sem influência do português até aquelas formadas com influência do português e que podem ser consideradas, então, empréstimos.

Quadro 2 - Continuum das formas toponímicas paranaenses: das mais nativas, ou seja, formadas com nenhuma ou menos influência do português (tons de vermelho) às formadas com maior influência dessa língua (tons de azul).

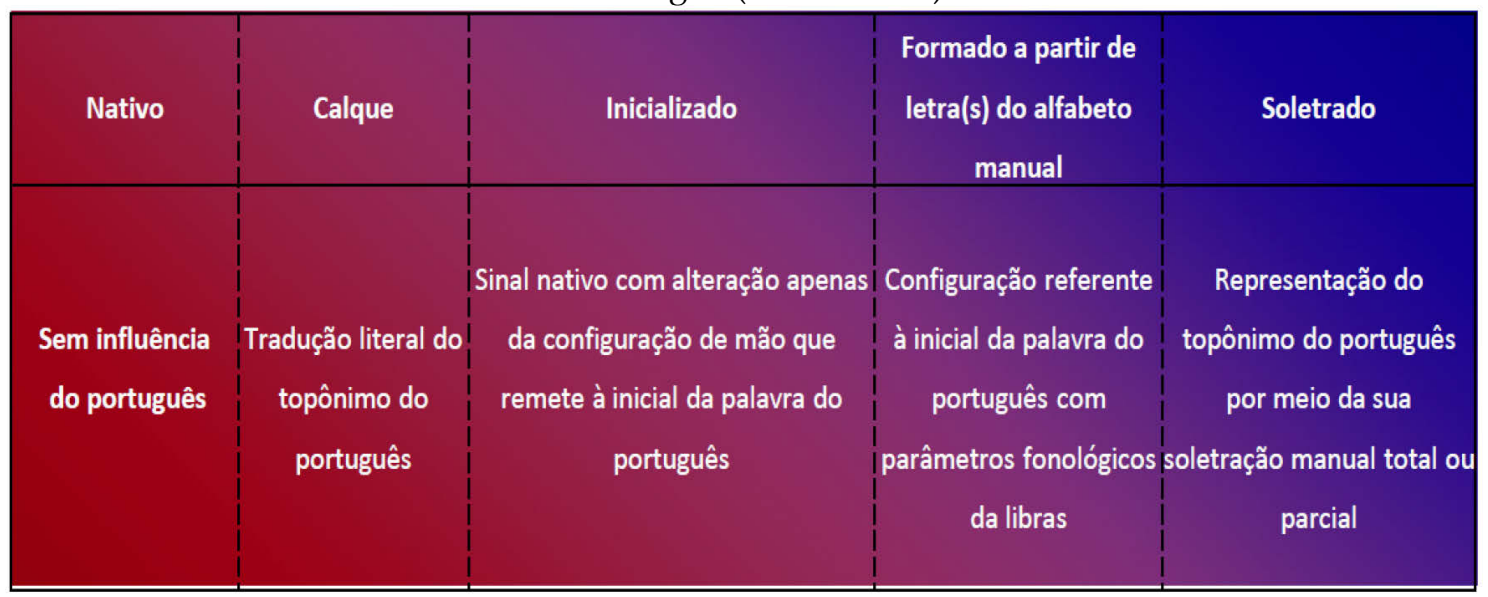

Fonte: elaborado pelos autores.

Empregamos tons de vermelho para representar a presença da Libras na constituição dos topônimos e tons de azul para representar a presença do português. A mescla das cores indica casos híbridos. A preponderância do vermelho no caso dos calques comparativamente aos sinais inicializados indica que, apesar da influência do português, os primeiros não sofreram alteração na sua forma tal como os segundos que tiveram sua configuração alterada. Os topônimos formados por letras, diferentemente dos dois tipos anteriores, apresentam predominância dos tons de azul, justamente porque, em nossa visão, a configuração, referente à inicial do topônimo correspondente em português, se destaca diante da pouca ou nula contribuição semântica dos outros parâmetros que os constituem. Por fim, vale dizer que no Quadro 2 os diferentes tipos de topônimos são separados por linhas pontilhadas para sugerir 
que nem sempre os limites entre essas categorias são claros. As linhas pontilhadas têm o objetivo de sugerir também a dificuldade de classificação de casos que ficam na fronteira entre dois tipos.

Este artigo $^{8}$ objetiva contribuir com um avanço na compreensão das características dos topônimos da Libras por meio da análise de sinais que nomeiam municípios de 14 estados e regiões administrativas do Distrito Federal. De forma específica, objetivamos, testar as categorias de análise propostas por Urbanski, Xavier e Ferreira (2019) e Ferreira e Xavier (2019) com um conjunto de dados, além de maior, referente a outros estados e, assim, validá-las.

\section{Metodologia}

O primeiro passo para a realização deste trabalho foi levantar no Youtube vídeos contendo sinais que nomeiam municípios de todos os estados brasileiros. Utilizaram-se como palavras-chave para a busca desses vídeos o nome do estado (ou do distrito federal), acrescido das palavras "cidades" e "Libras". Conforme se pode ver no Apêndice 1, foram encontrados vídeos referentes a 14 estados e às regiões administrativas do Distrito Federal.

Todos esses vídeos foram baixados e segmentados no Movie Maker para facilitar consultas posteriores. Na sequência, foram classificados no banco de dados do Access em relação à região e ao estado a que pertencem, à cidade que nomeiam, à sua origem (se nativos ou empréstimos do português), e, no caso de empréstimos, se formados por

\footnotetext{
${ }^{8}$ Este artigo é um desdobramento da pesquisa de iniciação científica do primeiro autor, realizada entre setembro de 2018 e setembro de 2019, bem como de seu Trabalho de Conclusão de Curso, desenvolvido ao longo de 2019 como requisito para a obtenção do grau de licenciado em Letras Libras pela UFPR. A iniciação científica foi orientada pelo terceiro autor e o trabalho de conclusão de curso pela segunda autora e pelo terceiro autor. Agradecemos à Fundação Araucária que, em parceria com a Superintendência de Inclusão, Políticas Afirmativas e Diversidade (SIPAD) da UFPR, deu suporte financeiro para o desenvolvimento desta pesquisa por meio da concessão de uma bolsa PIBIS.
} 
(1) calque, (2) soletração, (3) inicialização ou ainda (4) pela combinação de letras do alfabeto manual com outros parâmetros fonológicos da Libras. Os topônimos foram também classificados quanto à sua estrutura morfológica simples ou composta (Figuras 14 e 15).

Figura 14 - Categorias de análise.

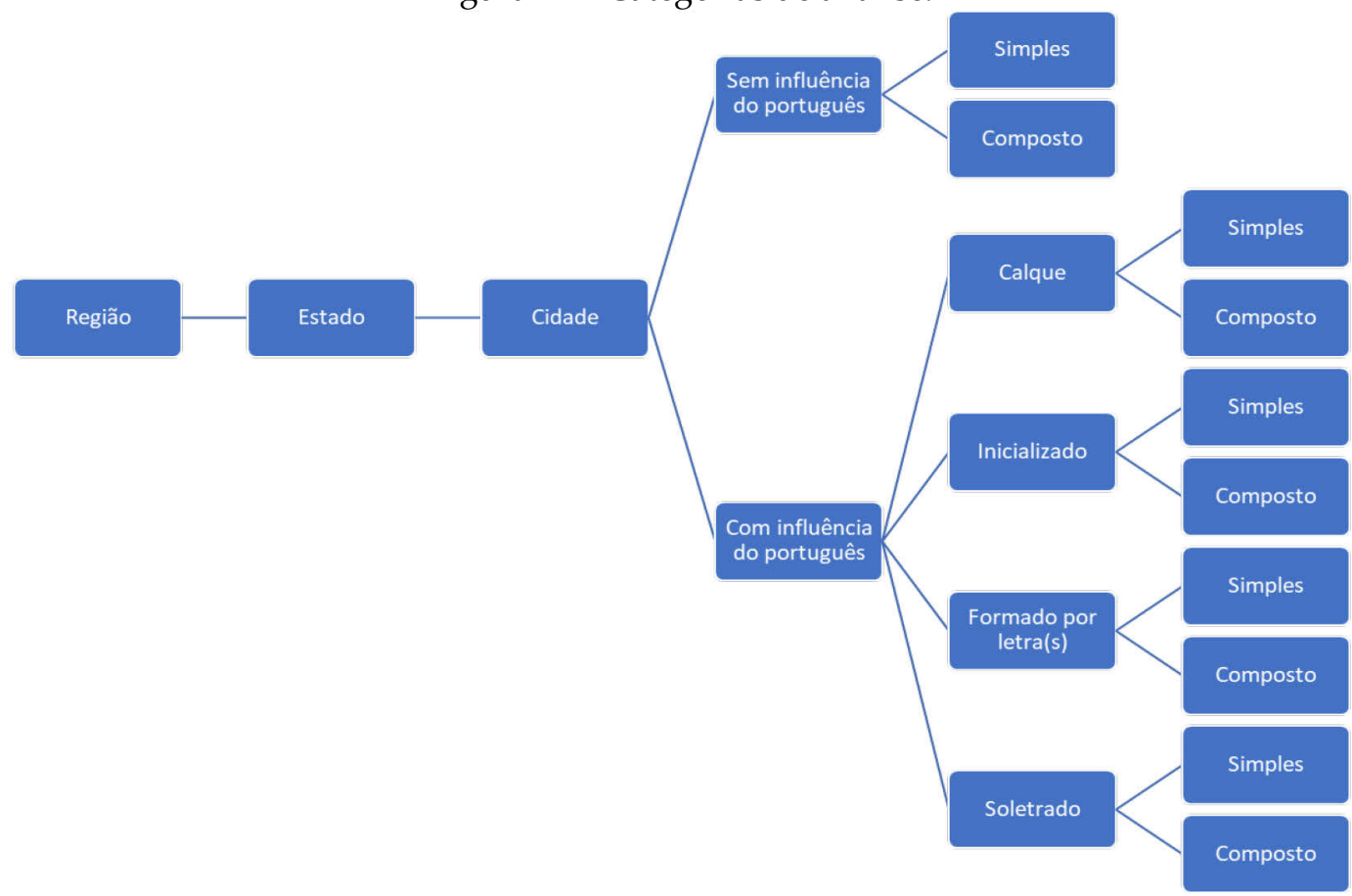

Fonte: elaborada pelos autores.

Figura 15 - Tela do Access.

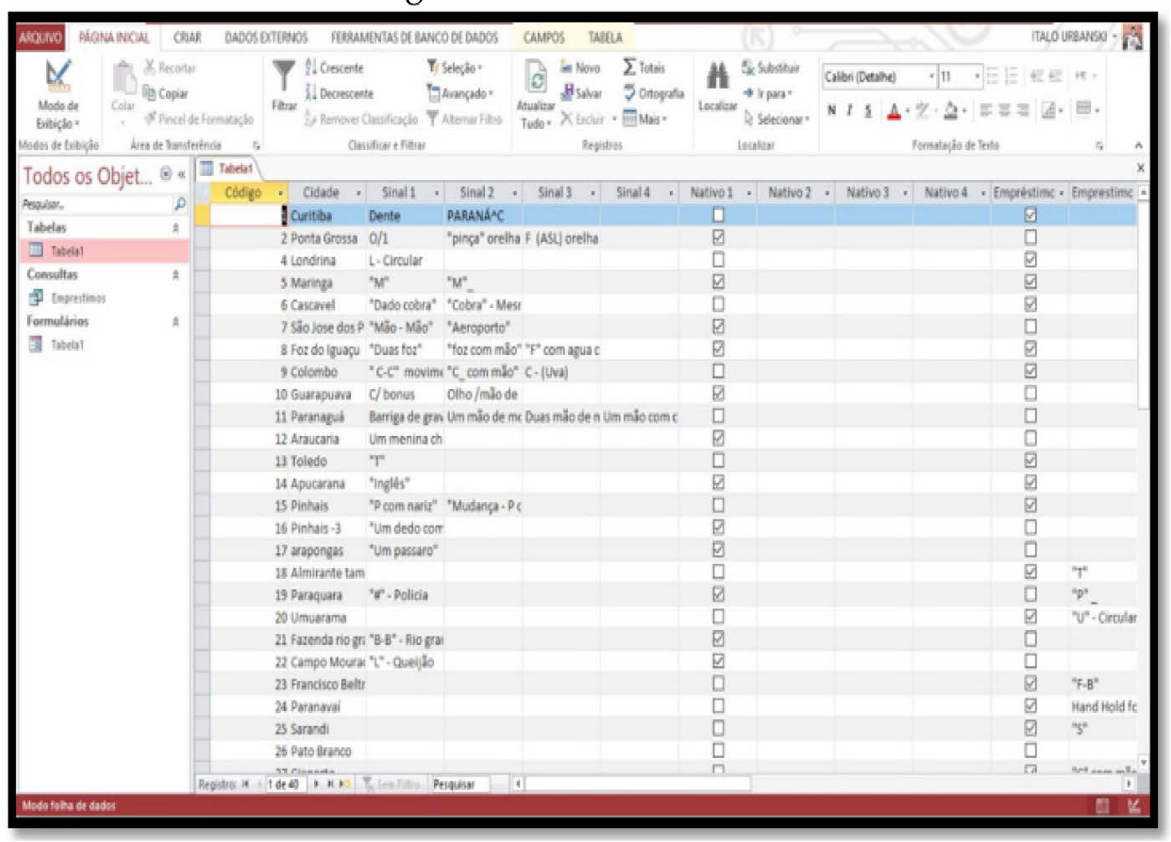

Fonte: elaborada pelos autores. 
As variantes lexicais identificadas foram incluídas no banco de dados. Excluímos, no entanto, as variantes fonológicas. Agrupamos na categoria 'dúvida' topônimos cuja classificação não nos pareceu clara.

É importante registrar que abandonamos o termo hibridismo empregado em publicações anteriores para designar topônimos constituídos de letras do alfabeto manual. Entendemos agora que tal termo é genérico e, portanto, capaz abranger também os demais casos de empréstimos. Em outras palavras, calques, soletrações e inicializações também podem ser vistos como formações híbridas, uma vez que elementos da Libras e do português estão simultaneamente presentes neles.

Entretanto, seguimos as categorias e subcategorias propostas por Urbanski, Xavier e Ferreira (2019) e Ferreira e Xavier (2019) para a categorização dos topônimos em análise. Classificamos como calques traduções literais de topônimos em português (cf. PATO-BRANCO, Figura 8a, PONTA-GROSSA, Figura 11c, e NOVO-MUNDO, Figura 13a).

Classificamos como topônimos formados por letras sinais que, embora, semelhantemente aos topônimos soletrados, sejam constituídos por configurações de mão do alfabeto manual, são, geralmente, articulados em localizações distintas e com movimentos diferentes dos tipicamente observados na soletração manual (cf. LONDRINA, Figura 7b, e CAMPO-SIQUEIRA, Figura 11b). Por outro lado, classificamos como topônimos soletrados sinais que, justamente por serem oriundos da soletração manual, apresentam localização (em frente ao ombro ipsilateral) e movimentos (resultantes da mudança de configuração ou do deslocamento lateral da mão) típicos desta (Cf. CORNÉLIO-PROCÓPIO, Figura 8b, e SÃO-FRANCISCO, Figura 13b) (NASCIMENTO, 2011).

Por fim, classificamos como inicializados sinais que, como IRATI (Figura 8c) e BATEL (Figura 13c), foram criados através da substituição da configuração de mão de 
um sinal já existente, respectivamente, FÓSFORO e IGREJA-BATISTA, por outra que remete, no alfabeto manual, à letra inicial do topônimo escrito em português.

Após o armazenamento de todas essas classificações e subclassificações no banco de dados do Access, foi possível realizar buscas e com isso determinar a frequência de cada categoria e subcategoria de análise no corpus por região e por estado. Os resultados dessas buscas foram registrados no programa Excel do pacote Office da Microsoft, o qual permitiu a criação dos gráficos que serão apresentados na próxima seção.

\section{Resultados}

Conforme mostra a Tabela 1, foram coletados topônimos referentes a 816 municípios brasileiros e regiões administrativas do D.F. Isso representa $20 \%$ dos municípios e regiões administrativas contidos pelos 14 estados e pelo D.F. Foram coletadas também 72 variantes lexicais para alguns desses topônimos, o que explica o total de 888 dados.

Tabela 1 - Dados.

\begin{tabular}{|c|c|c|c|c|c|}
\hline Região & $\begin{array}{l}\text { Estado/ } \\
\text { Distrito } \\
\text { Federal }\end{array}$ & $\begin{array}{c}\text { Quantidade de municípios/ } \\
\text { Regiões } \\
\text { Administrativas }\end{array}$ & $\begin{array}{l}\text { Sinais } \\
\text { obtidos }\end{array}$ & $\begin{array}{c}\text { Variantes } \\
\text { lexicais }\end{array}$ & Total \\
\hline Norte & $\begin{array}{l}\text { Acre } \\
\text { Pará }\end{array}$ & $\begin{array}{c}22 \\
144\end{array}$ & $\begin{array}{l}22 \\
16 \\
\end{array}$ & $\begin{array}{l}1 \\
0\end{array}$ & $\begin{array}{l}23 \\
16 \\
\end{array}$ \\
\hline Nordeste & $\begin{array}{c}\text { Ceará } \\
\text { Pernambuco } \\
\text { Maranhão } \\
\text { Rio Grande do } \\
\text { Norte }\end{array}$ & $\begin{array}{l}184 \\
185 \\
217 \\
167\end{array}$ & $\begin{array}{c}184 \\
34 \\
12 \\
18\end{array}$ & $\begin{array}{c}24 \\
3 \\
0 \\
0\end{array}$ & $\begin{array}{c}208 \\
37 \\
12 \\
18\end{array}$ \\
\hline $\begin{array}{c}\text { Centro- } \\
\text { Oeste }\end{array}$ & $\begin{array}{c}\text { Mato Grosso Mato } \\
\text { Grosso do Sul } \\
\text { DF }\end{array}$ & $\begin{array}{c}141 \\
79 \\
33\end{array}$ & $\begin{array}{l}86 \\
79 \\
49\end{array}$ & $\begin{array}{l}5 \\
7 \\
5\end{array}$ & $\begin{array}{l}91 \\
86 \\
54\end{array}$ \\
\hline Sudeste & $\begin{array}{l}\text { Minas Gerais } \\
\text { São Paulo } \\
\text { Espírito Santo }\end{array}$ & $\begin{array}{c}853 \\
645 \\
78\end{array}$ & $\begin{array}{c}100 \\
41 \\
19\end{array}$ & $\begin{array}{l}1 \\
1 \\
0\end{array}$ & $\begin{array}{c}101 \\
42 \\
19\end{array}$ \\
\hline Sul & $\begin{array}{c}\text { Paraná } \\
\text { Santa Catarina } \\
\text { Rio Grande do Sul }\end{array}$ & $\begin{array}{l}399 \\
295 \\
497\end{array}$ & $\begin{array}{l}67 \\
66 \\
23\end{array}$ & $\begin{array}{c}24 \\
0 \\
1\end{array}$ & $\begin{array}{l}91 \\
66 \\
24\end{array}$ \\
\hline Total & 15 & 3.939 & 816 & 72 & 888 \\
\hline
\end{tabular}

Fonte: produzida pelos autores. 
De maneira geral, os resultados indicam uma predominância, entre os topônimos analisados, de empréstimos (Figura 16a) e, entre estes, de sinais formados a partir de letra(s) do alfabeto manual (Figura 16b). Somando-se a isso, eles indicam também que predominam topônimos simples.

Figura 16. Frequência dos topônimos formados sem (a) e com influência do português e, no último caso, nas diferentes subcategorias de formação $(b)$.

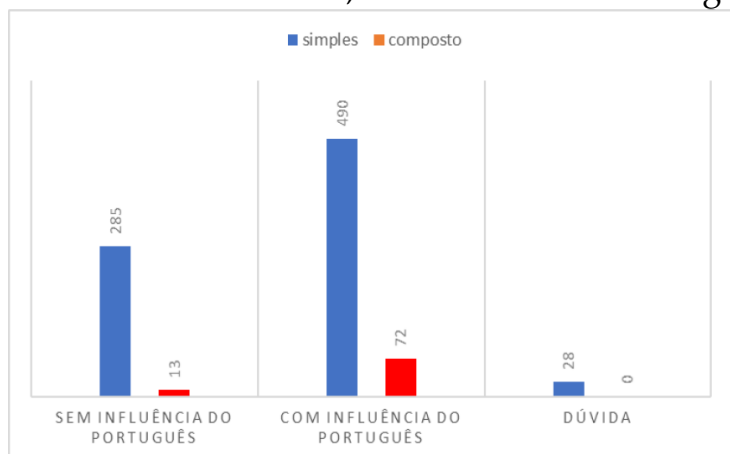

(a)

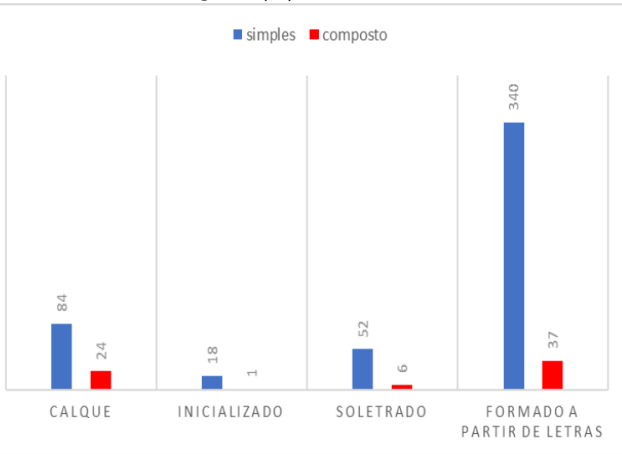

(b)

Fonte: produzida pelos autores.

Comparando os dados analisados por regiões, observou-se que eles não diferem em relação aos resultados gerais. Nas cinco regiões, representadas pelos dados a que tivemos acesso, predominam topônimos formados com influência do português, ou seja, empréstimos, e, dentre eles, os formados pela combinação de letras do alfabeto manual com outros parâmetros fonológicos da Libras (Figura 17). 
Figura 17 - Frequência de topônimos (a) formados sem e com influência do português e, dentre os últimos, (b) por calque, inicialização, soletração ou letras do alfabeto manual.

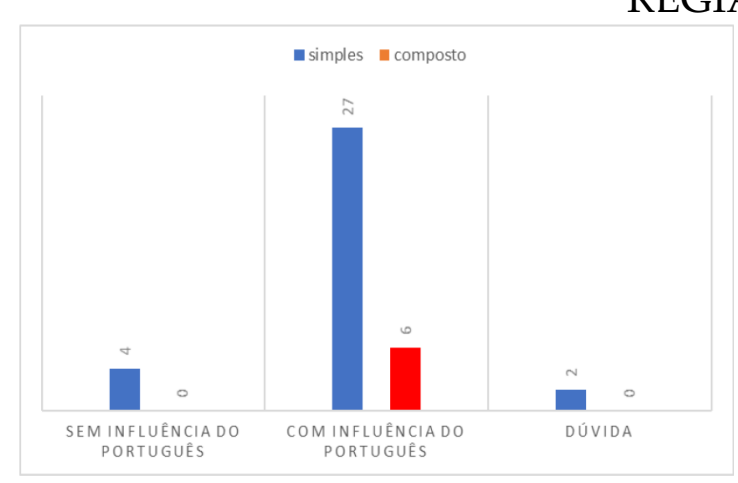

(a)

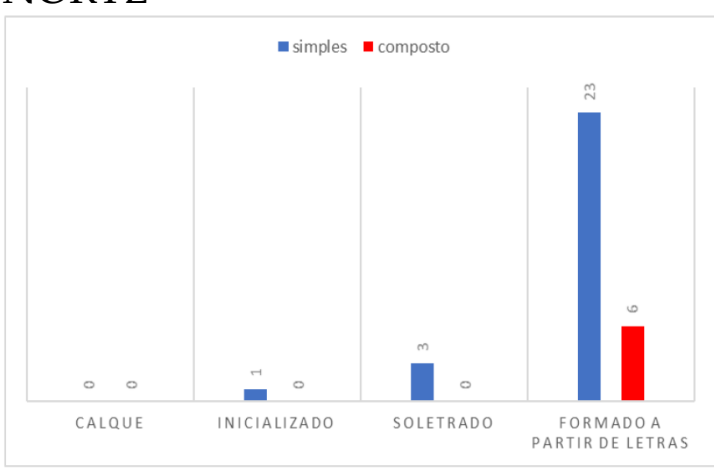

(b)

\section{REGIÃO NORDESTE}

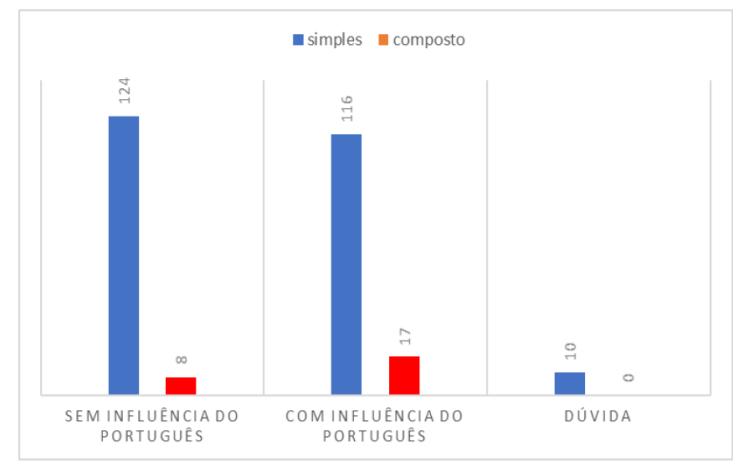

(a)

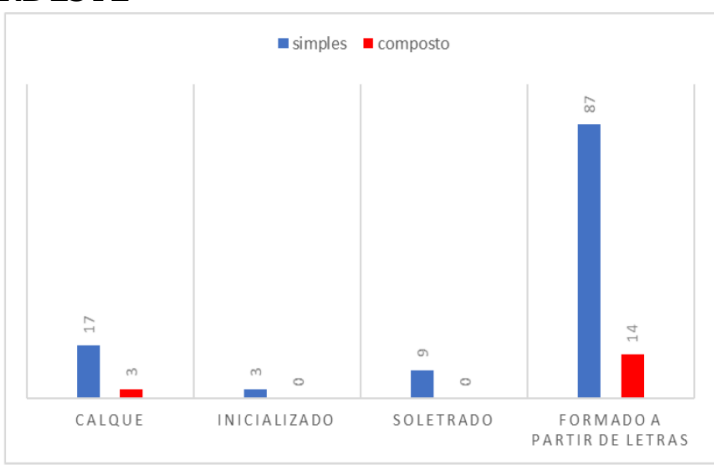

(b)

\section{REGIÃO CENTRO-OESTE}

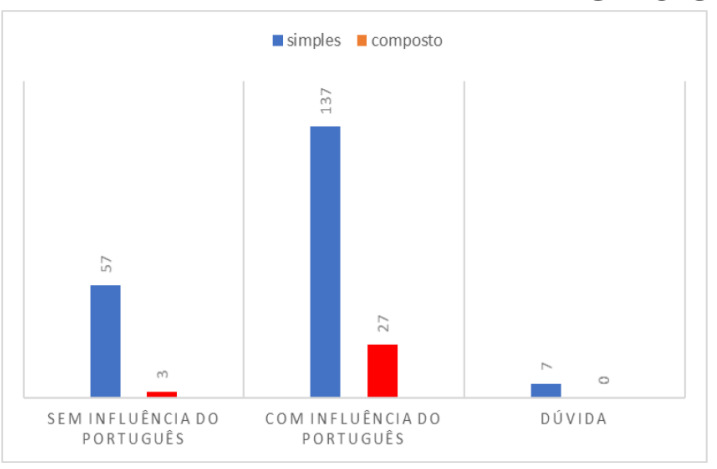

(a)

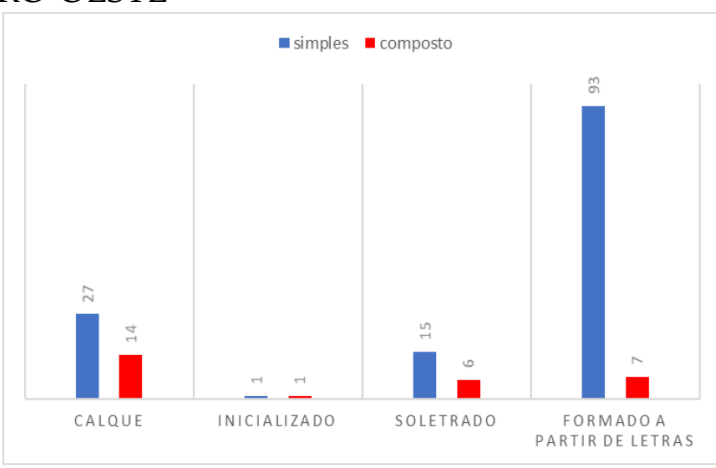

(b) 


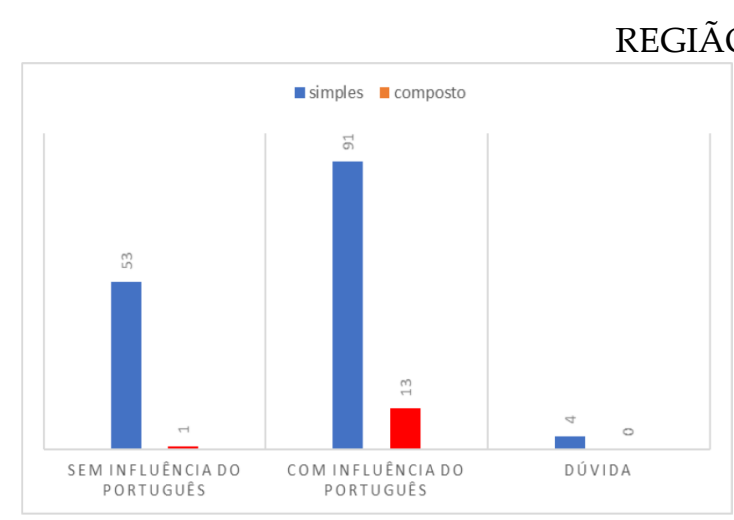

(a)

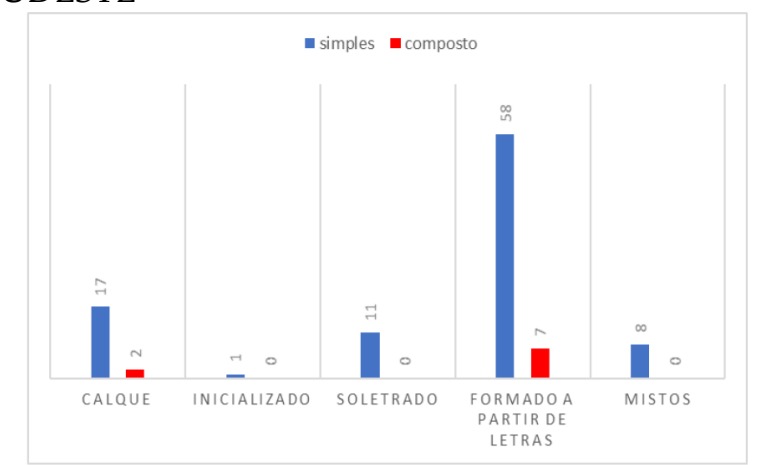

(b)

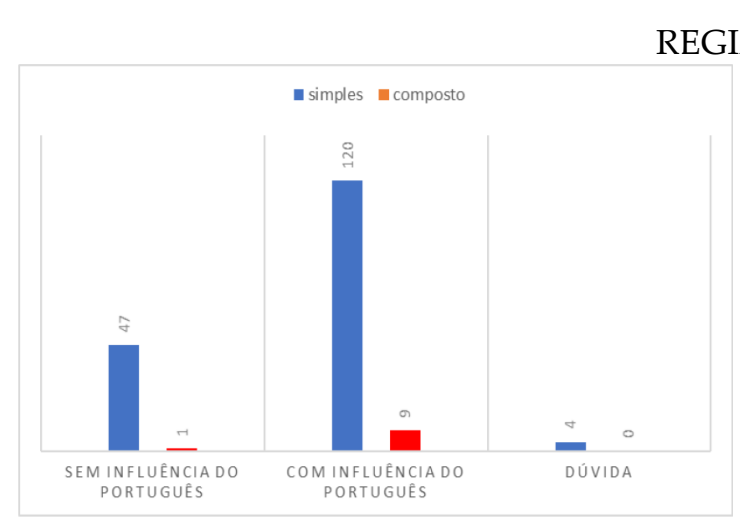

(a)

Fonte: produzida pelos autores.

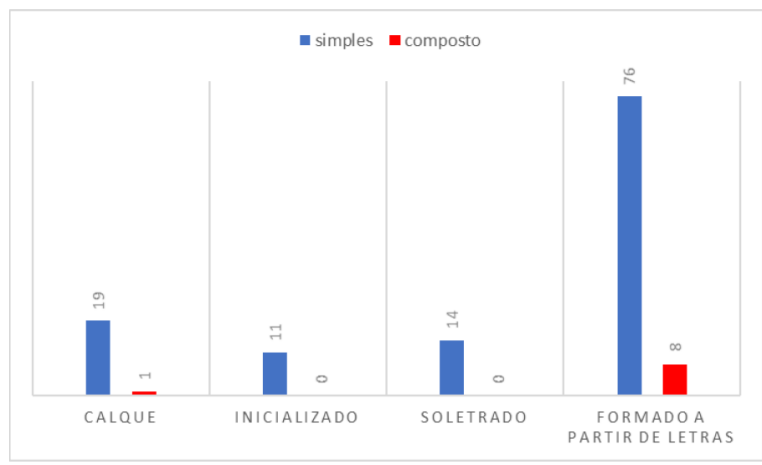

(b)

A seguir, ilustraremos os cinco tipos de formações toponímicas identificados nos dados com base em sinais simples, que representam 90,5\% dos casos. Como ilustração dos topônimos de diferentes regiões formados aparentemente sem influência do português podemos citar os sinais da Figura 18. Embora muito provavelmente todos eles sejam, na origem, motivados por algum aspecto dos espaços geográficos que nomeiam (DICK, 1990), conhecemos a motivação de apenas dois deles. De acordo com Sousa e Quadros (2019a), o sinal de XAPURI (AC) (Figura 18a) faz "referência ao trabalho do seringueiro na extração do látex" (p. 70). Já a motivação do sinal para BRASÍLIA (Figura 18b) é anedoticamente relacionada com o formato do brasão da cidade. 
Figura 18 - Exemplos de sinais formados sem influência do português.

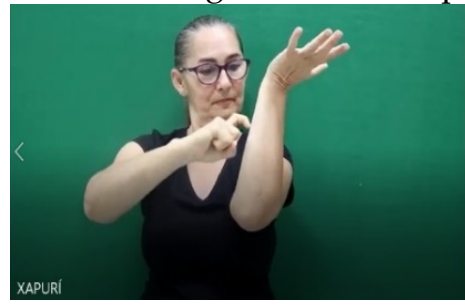

XAPURI (AC)

(a)

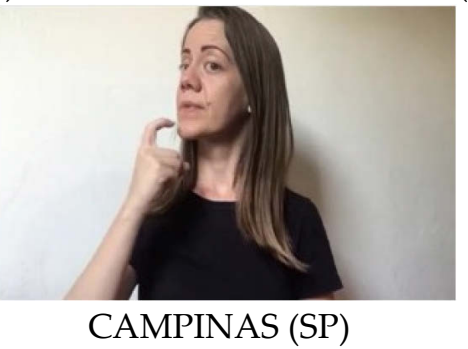

(d)

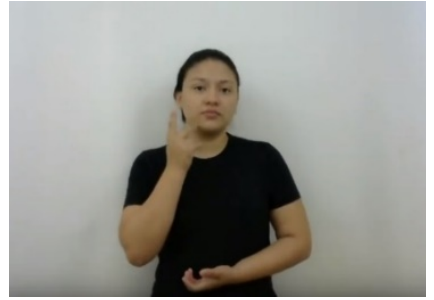

FORTALEZA (CE)

(b)

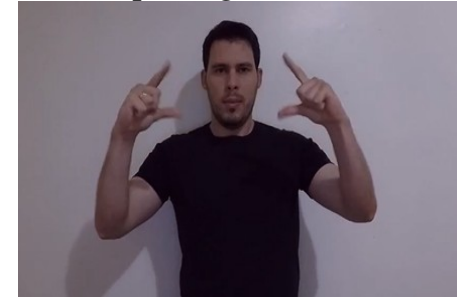

BRASÍLIA (DF)

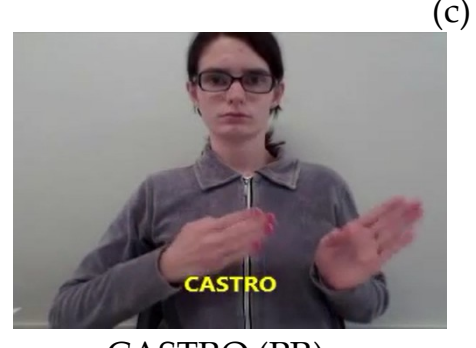

CASTRO (PR)

(e)

Fonte: (a) https://www.youtube.com/watch?v=C2YAyUQwUCY;

(b) https://redesurdosce.ufc.br/municipios-do-ceara/i

(c) https://www.youtube.com/watch?v=Zrf2yKnnAAk;

(d) https://www.youtube.com/watch?v=-mJJhwhuWJU;

(e) https://www.youtube.com/watch?v=lLYhPg_jNIQ.

Para ilustrar casos de topônimos da Libras de diferentes regiões categorizados como calques, citamos os exemplos na Figura 19. Esses sinais foram assim tratados em razão de representarem traduções literais ou aproximadas do topônimo do português para a Libras. Diferentemente dos sinais formados sem influência do português, o sinal empregado é motivado pelo significado do topônimo dessa língua. Isso explica o uso do sinal CHORAR para Chorozinho (CE) (Figura 19a), LOBO para Guará (DF), ÓLEO para Óleo (SP) (Figura 19c) e COBRA para Cascavel (PR) (Figura 19d).

Figura 19 - Exemplos de sinais formados por calque

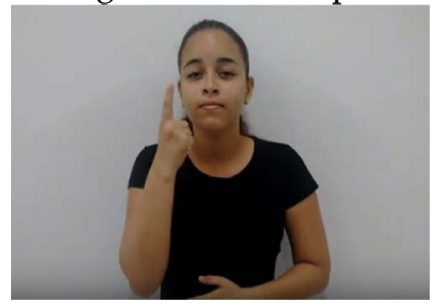

CHOROZINHO (CE)

(a)

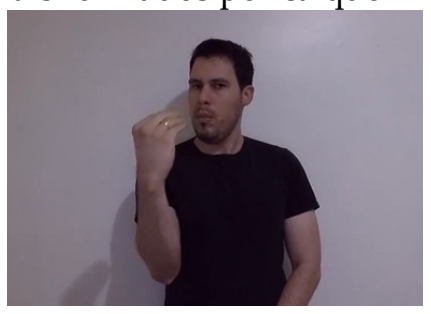

GUARÁ (DF)

(b) 


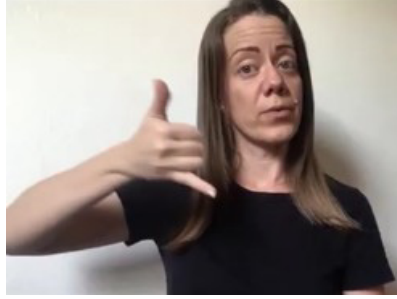

ÓLEO (SP)

(c)

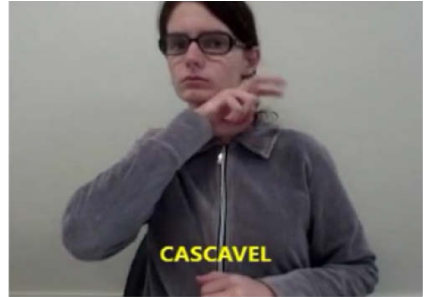

CASCAVEL (PR)

(d)

Fonte: (a) https://redesurdosce.ufc.br/municipios-do-ceara/i

(b) https://www.youtube.com/watch?v=Zrf2yKnnAAk;

(c) https://www.youtube.com/watch?v=-mJJhwhuWJU;

(d) https://www.youtube.com/watch?v=lLYhPg_jNIQ.

Topônimos formados por inicialização também foram identificados nos dados das cinco regiões. Como se pode depreender da Figura 20, esses sinais foram assim categorizados porque resultam da substituição da configuração de um sinal já existente por outra que compõe o alfabeto manual e, por essa razão, pode remeter à letra inicial do topônimo em português. Dessa perspectiva, o sinal BELÉM (PA) (Figura 20a) deriva, por inicialização, do sinal PARÁ através da substituição da configuração "mão plana" deste sinal pela configuração em B, que remete à inicial do topônimo Belém em português. Os sinais RUSSAS (CE) (Figura 20b), SANTA-RITADO-PARDO (MT) (Figura 20c) e IRATI (PR) (Figura 20e), por sua vez, resultam da substituição da configuração da mão ativa de seu respectivo sinal primitivo, CIDADE, NOSSA-SENHORA e FÓSFORO, pela configuração que remete à letra inicial do topônimo correspondente em português, respectivamente, R, S-R e I. Por fim, o sinal ANCHIETA (ES) (Figura 20d) é formado por meio da alteração da configuração da mão "em concha" de BARCO pela configuração em A. Pela imagem, vê-se que, embora o sinal seja realizado com as duas mãos ativas, a substituição da configuração só se dá na mão dominante. 
Figura 20 - Exemplos de sinais formados por inicialização.

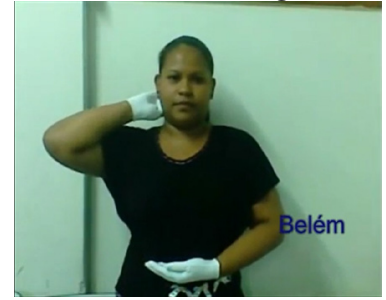

BELÉM (PA)

(a)

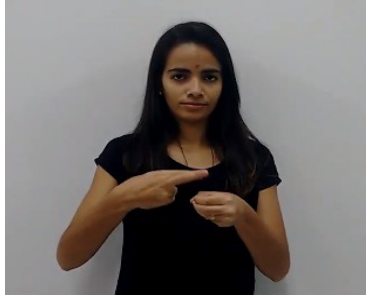

RUSSAS (CE)

(b)

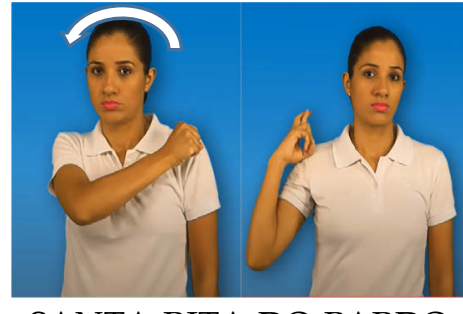

SANTA-RITA-DO-PARDO

(MS)

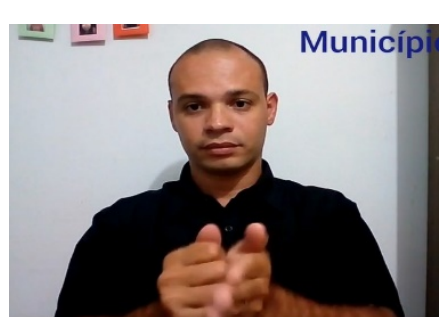

ANCHIETA (ES)

(d)

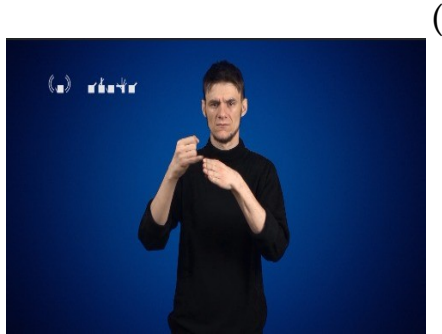

IRATI (PR)

(e)

Fonte: (a) https://www.youtube.com/watch?v=05JqJtCnQfY;

(b) https://redesurdosce.ufc.br/municipios-do-ceara/;

(c) https://www.youtube.com/watch?v=u6hPV7GfphA;

(d) https://www.youtube.com/watch?v=X6uV-TxgkqI;

(e) https://youtu.be/EY8CRSi1HAU.

Ilustrações de topônimos da Libras formados por letra(s) e outros parâmetros fonológicos da Libras são mostrados na Figura 21. Nela, vê-se o sinal RODRIGUESALVES (AC) (Figura 21a) formado por duas configurações de mão que remetem às iniciais do referido nome, ' $r$ ' e 'a', bem como os sinais HORIZONTE (CE) (Figura 21b) (Figura 21b), BRAZLÂNDIA (DF) (Figura 21c), BETIM (MG) (Figura 21d) e GRAMADO (RS) (Figura 21e), constituídos apenas por uma configuração, que remete à inicial do topônimo correspondente em português. Como se verá, esses sinais diferem dos soletrados, a serem apresentados a seguir, justamente, porque não são produzidos na localização típica da soletração manual. Observe que RODRIGUESALVES é articulado sobre o antebraço e BETIM sobre o dorso da mão não dominante. O movimento pode ser um outro traço que distingue formações desse tipo dos casos de topônimos soletras. Como se pode ver, diferentemente do movimento retilíneo típico da soletração manual, HORIZONTE (CE) e BRAZLÂNDIA (DF), apresentam 
movimentos repetidos de girar o antebraço, enquanto GRAMADO (RS) exibe movimento em arco.

Figura 21 - Exemplos de sinais formados por letras do alfabeto manual.

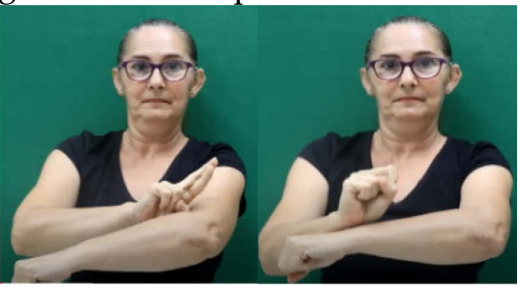

RODRIGUES-ALVES (AC)

(a)

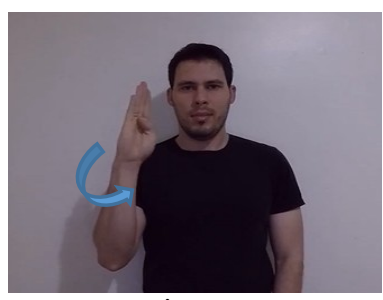

BRAZLÂNDIA (DF)

(c)

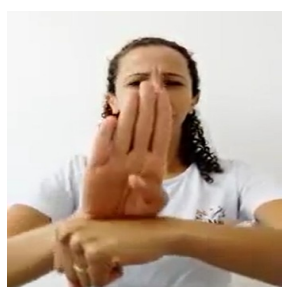

$\operatorname{BETIM}(\mathrm{MG})$

(d)

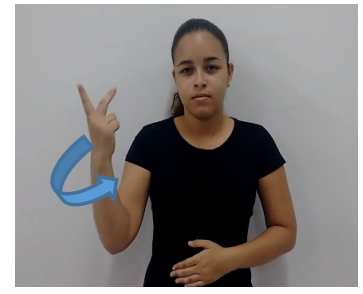

HORIZONTE (CE)

(b)

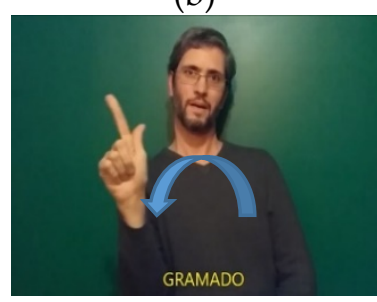

GRAMADO (RS)

(e)

Fonte: (a) https://www.youtube.com/watch?v=C2YAyUQwUCY;

(b) https://redesurdosce.ufc.br/municipios-do-ceara/i

(c) https://www.youtube.com/watch?v=Zrf2yKnnAAk;

(d) https://www.youtube.com/watch?v=hs9svNvHfPQ;

(e) https://www.youtube.com/watch?v=jKquphgkeVk.

Exemplos de topônimos expressos por meio da soletração manual foram identificados em todas as regiões. Por exiguidade de espaço, as imagens na Figura 22 só mostram a primeira letra de cada palavra. Entretanto, em todos esses topônimos a palavra do português é completamente soletrada, ou seja, não ocorre fusões ou supressões de letras do alfabeto manual. Além disso, todas elas exibem a localização e o movimento típicos de soletrações manuais, o que, como já dito, os difere dos sinais formados por letras de (21). 
Figura 22 - Exemplos de sinais formados por soletração.

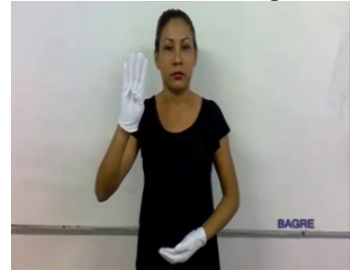

B-A-G-R-E (PA)

(a)

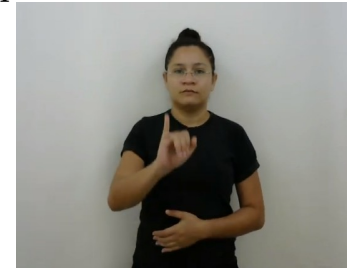

I-C-Ó (CE)

(b)

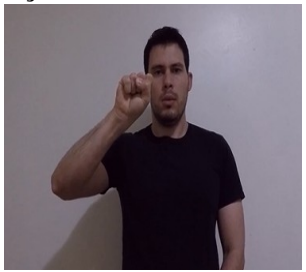

S-I-A (DF)

(c)

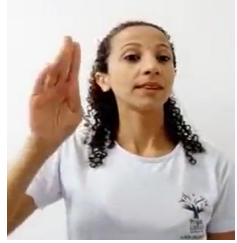

B-H (MG)

(d)

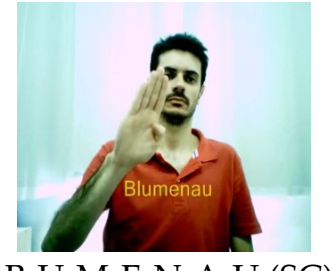

B-U-M-E-N-A-U (SC)

(e)

Fonte: (a) https://www.youtube.com/watch?v=05JqJtCnQfY;

(b) https://redesurdosce.ufc.br/municipios-do-ceara/;

(c) https://www.youtube.com/watch?v=Zrf2yKnnAAk;

(d) https://www.youtube.com/watch?v=hs9svNvHfPQ;

(e) https://www.youtube.com/watch?v=iYiwrWCDW1o.

Topônimos compostos sequenciais foram menos frequentes, representando apenas 9,5\% dos dados. Como ilustração dessas formações, citamos os sinais em (23). TAQUARUSSU (MS) (Figura 23a) exemplifica topônimos formados sem influência do português, uma vez que os sinais que o constituem, ÁRVORES e RIO, diferentemente dos que formam BOM-JESUS (PI) (Figura 23b) e traduzem literalmente o topônimo em português, devem representar aspectos visuais do local designado. ALTA-FLORESTA (MT) (Figura 23c), por sua vez, é formado por FLOR e ALT@, este último constituído por inicialização, justamente porque nele a configuração em 1 do segundo sinal é substituída pela configuração em F, que remete à segunda palavra do topônimo correspondente em português. Por fim, LAGOA-DA-PRATA (MG) (Figura 23d) e JANUÁRIA (MG) (Figura 23e) ilustram, respectivamente, um composto formado por letra e outro formado por soletração. Precisamente, no primeiro caso, a formação por letra se encontra na primeira parte do composto, realizada com a mão dominante, configurada em L em referência à 
inicial do topônimo do português, fazendo um círculo em volta da mão não dominante, configurada em S. Já no segundo topônimo, a primeira parte do sinal constitui-se da sinalização da letra J, inicial do topônimo correspondente em português. No caso de JANUÁRIA (MG), observa-se também a presença de um sinal, o segundo especificamente, sem relação com o português.

Figura 23 - Exemplos de topônimos compostos: (a) nativo, (b) calque, (c) inicializado/calque, (d) formado por letra/calque e (e) soletrado/nativo/calque.

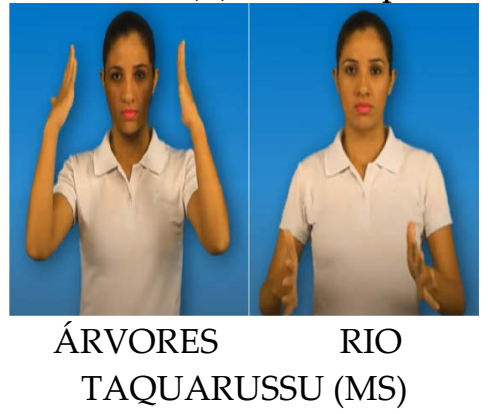

(a)

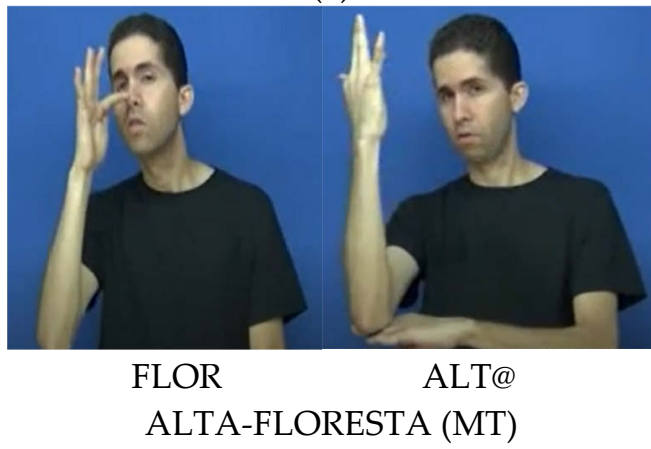

(c)

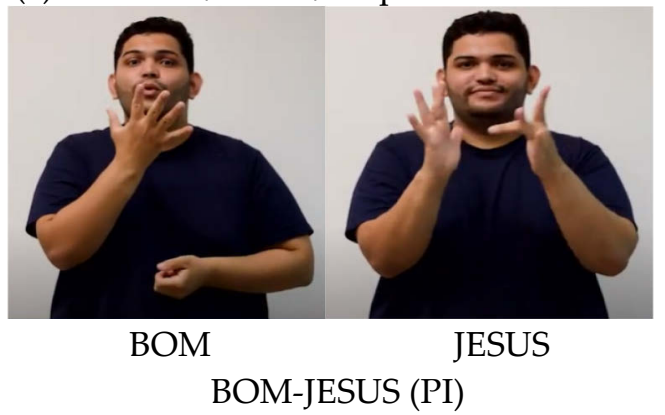

(b)

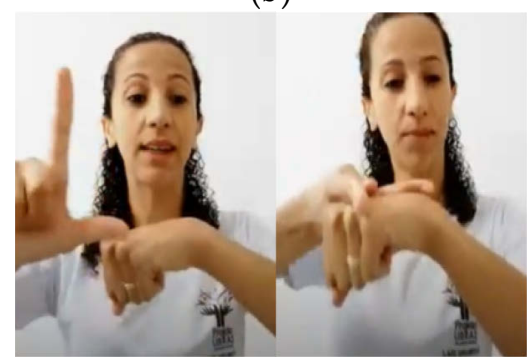

LAGOA PRATA LAGOA-DA-PRATA (MG)

(d)

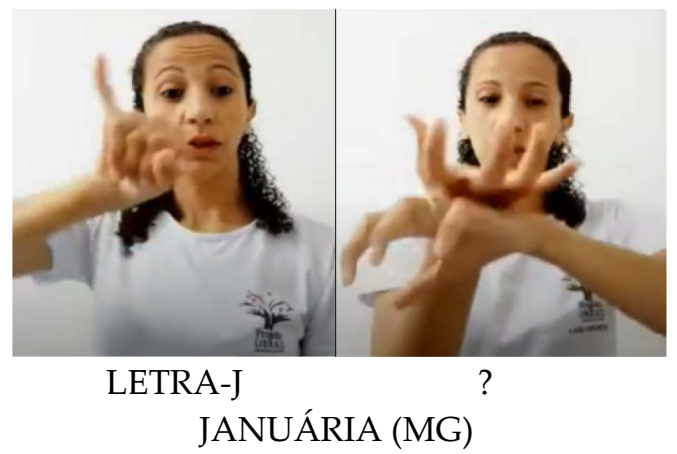

(e)

Fonte: (a) https://www.youtube.com/watch?v=u6hPV7GfphA;

(b) https://youtu.be/EY8CRSi1HAU;

(c) https://www.youtube.com/watch?v=sqE_HW5Qp98;

(d-e) https://www.youtube.com/watch?v=hs9svNvHfPQ. 
Embora os resultados referentes às cinco regiões brasileiras sugiram que estas não se diferenciem entre si em relação à frequência dos diferentes tipos de topônimos da Libras (Figura 17), a comparação entre os estados revelou que os topônimos do Ceará se distinguem dos demais justamente por terem sido, em sua maioria, criados sem a influência do português (Figura 24a). Apesar disso, entre os empréstimos, os topônimos referentes aos municípios do Ceará seguem a tendência geral, ou seja, são predominantemente formados a partir de letras do alfabeto manual (Figura 24b).

Figura 24 - Frequência, por categoria e subcategoria, dos topônimos do Ceará.

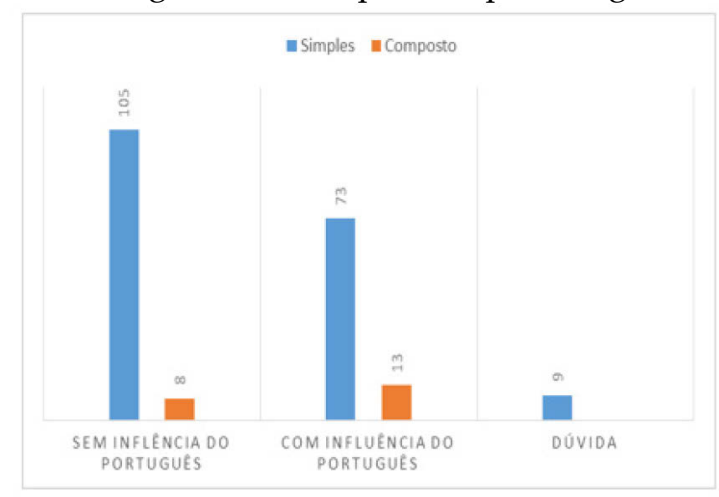

(a)

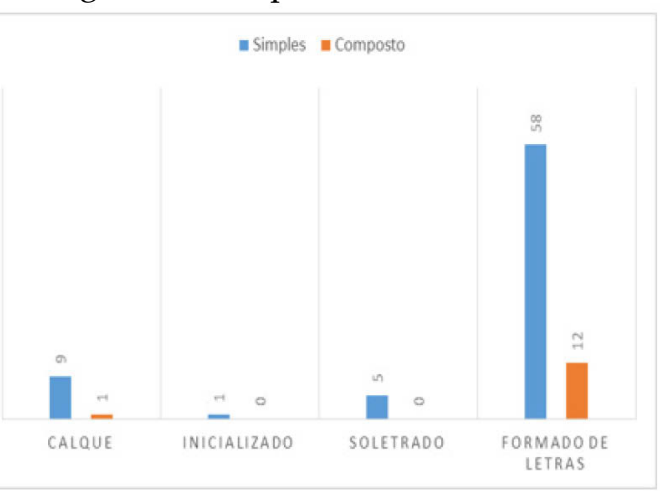

(b)

Fonte: produzida pelos autores.

A análise desses 888 topônimos revelou ainda a existência de casos mistos, ou seja, de topônimos formados por mais de um dos processos observados entre os empréstimos. Entre os sinais simples, um exemplo desses casos é o sinal para o município Rio Acima (MG), no qual se vê não apenas a inicialização (substituição da configuração típica do sinal RIO pela configuração referente à letra R), mas também uma tradução literal do topônimo do português, calque, dado que o sinal RIO é feito com movimento para cima e não para frente (Figura 25). 
Figura 25 - Topônimo formado por mais de um processo.

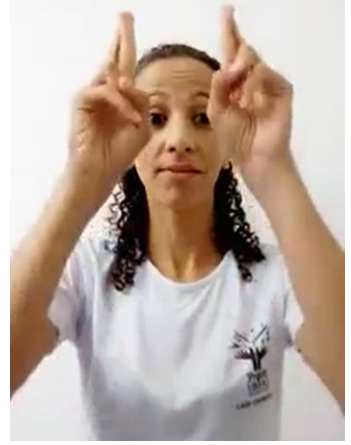

Fonte: https://www.youtube.com/watch?v=hs9svNvHfPQ.

Já entre os compostos, podemos citar os sinais ALTA-FLORESTA (MT) (Figura 23c) e LAGOA-DA-PRATA (Figura 23d). Conforme descrito anteriormente, tais sinais incluem em suas formações, respectivamente, um sinal inicializado e um sinal formado a partir de uma letra do alfabeto manual. Simultaneamente, o composto é formado por calque, uma vez que a seleção e ordem de suas partes espelham o topônimo correspondente em português.

\section{Considerações finais}

Com base na pesquisa de Urbanski, Xavier e Ferreira (2019) e Ferreira e Xavier (2019), este trabalho objetivou contribuir com a descrição de topônimos da Libras, determinando se são nativos, ou seja, formados sem influência do português, ou empréstimos, isto é, formados com alguma influência do português. Neste último caso, determinou-se também se os topônimos coletados resultam de tradução literal (calque), soletração, inicialização ou se são formados a partir de letras do alfabeto manual combinadas com outros parâmetros da Libras.

De forma geral, os resultados aqui reportados reforçam os obtidos por Souza- Júnior (2012), Aguiar (2012), Sousa e Quadros (2019a), Urbanski, Xavier e Ferreira e Ferreira e Xavier, uma vez que entre os 888 topônimos coletados de vídeos do Youtube predominam empréstimos do português. Essa tendência só 
não foi confirmada nos dados do Ceará, único estado cujos topônimos referentes a seus municípios são predominantemente nativos.

O presente estudo também mostrou que, semelhantemente a Urbanski, Xavier e Ferreira e Ferreira e Xavier, são mais frequentes entre os empréstimos os topônimos formados por letras. Adicionalmente, evidenciou-se também a existência de topônimos mistos, ou seja, formados por mais de um dos quatro processos identificados entre os empréstimos. Tal fato não invalida as categorias que propomos em trabalhos anteriores. Como se viu, elas puderam ser aplicadas à maioria dos dados e, nos casos mistos, ofereceram recursos para decompô-los analiticamente em termos delas.

Por se tratar de um estudo baseado em apenas 888 topônimos da Libras, os quais correspondem a 20\% dos municípios dos 14 estados e das regiões administrativas do Distrito Federal, os resultados aqui reportados devem ser tomados com cautela. As regiões não foram representadas de forma equilibrada, tampouco os estados. Há muito trabalho ainda por fazer, não apenas em termos amostrais, mas também em relação ao aprofundamento da análise das categorias e subcategorias aqui propostas.

\section{Referências Bibliográficas}

ADAM, R. Language contact and borrowing. In: PFAU, R.; STEINBACH, M.; WOLL, B. (org.). Sign language: An international handbook. Berlin: Mouton de Gruyter, 2012. p. 841-861. DOI https://doi.org/10.1515/9783110261325.841

AGUIAR, M. C. de. Descrição e análise dos sinais topônimos da Libras. In: ALBRES, N. A.; XAVIER, A. N. (org.). Libras em estudo: descrição e análise. São Paulo: FENEIS, 2012. p. 109-121.

CAPOVILLA, F. C.; RAPHAEL, W. D.; MAURÍCIO, A. C. L. Novo Deit-Libras: Dicionário Enciclopédico Ilustrado Trilíngue da Língua de Sinais Brasileira (Libras) 
baseado em Linguística e Neurociências Cognitivas, Volume 1 e 2. São Paulo: Editora da Universidade de São Paulo: Inep/Cnpq/Capes, 2009.

CAMPELO, A. R. de S.; LESSER, V. A. de S. Introdução da letra sinalizada como empréstimo linguístico nas noventa e duas cidades do estado do Rio de Janeiro: fato natural? In: CASTRO JÚNIOR, G. de; PROMETI, D.; TUXI, P.; RODRIGUES, S. Anais do I Congresso Internacional de Lexicologia, Lexicografia, Terminologia e Terminografia das Línguas de Sinais e II Fórum Internacional sobre Produção de Glossários e Dicionários em Línguas de Sinais. 1. ed., v. 1. Curitiba: Appris, 2019. p. 294-313.

CHAIBUE, K. Onomástica e Libras em Formosa-GO. Dissertação (Mestrado em Estudos Linguísticos) - Universidade Federal de Goiás, Goiânia, em preparação.

CHAVES, M. M.; LOBATO, H. K. G; SILVA, L. F. R. O nome de lugares na língua de sinais brasileira e a análise de três localidades do estado do Pará. In: CASTRO JÚNIOR, G. de; PROMETI, D.; TUXI, P.; RODRIGUES, S. Anais do I Congresso Internacional de Lexicologia, Lexicografia, Terminologia e Terminografia das Línguas de Sinais e II Fórum Internacional sobre Produção de Glossários e Dicionários em Línguas de Sinais. 1. ed., v. 1. Curitiba: Appris, 2019. p. 373-383.

DICK, M. V. de P. Toponímia e Antroponímia no Brasil. Coletânea de Estudos. 2 ed. São Paulo: FFLCH/USP, 1990.

FERREIRA, D.; XAVIER, A. N. Topônimos na Libras: análise preliminar de sinais que designam bairros de Curitiba. In: XXI SEMANA DE LETRAS - UFPR - Universidade Federal do Paraná, Volume II, Curitiba, Trabalhos completos [...]. p. 6-18, 2019.

FERREIRA, D. B. dos S. Estudo toponímico do centro comercial de Feira de SantanaBA: línguas orais e Libras. 186f. Dissertação (Mestrado em Estudos Linguísticos) Universidade Estadual de Feira de Santana, Feira de Santana, 2019.

FRANCISQUINI, I. de A. O nome e o lugar: uma proposta de estudos toponímicos da microrregião de Paranaval. 1998. 255 f. Dissertação (Mestrado) - UEL, Londrina, 1998.

JESUS, C. M. A. de. Estudo toponímico dos bairros de Feira de Santana-BA: línguas orais e Libras. 169f. Dissertação (Mestrado em Estudos Linguísticos) - Universidade Estadual de Feira de Santana, Feira de Santana, 2019. 
MIRANDA, R. G. de. Toponímia em Libras: descrição dos sinais dos municípios do Tocantins. Dissertação (Mestrado em Letras) - Universidade Federal do Tocantins, Porto Nacional, 2020.

NASCIMENTO, C. B. Alfabeto manual da língua de sinais brasileira (Libras): uma fonte produtiva para importar palavras da língua portuguesa. Revista Trama, v. 7, n. 14, p. 33-55, 2011.

NUNES, R. de J. Os sinais de denominações municipais de Sergipe em Libras: descrição e análise. 80f. Trabalho de Conclusão de Curso (Especialização em Libras) Faculdade de Administração e Negócios de Sergipe FANESE, Aracaju, 2018.

SOUZA-JÚNIOR, J. E. G. de. Nomeação de lugares na língua de sinais brasileira. Uma perspectiva de toponímia por sinais. 2012. 346 f. Dissertação (Mestrado em Letras) - UnB. Brasília, 2012.

SOUSA, A. M. de; QUADROS, R. M. Toponímia em Libras: aspectos formais e motivacionais dos sinais toponímicos dos municípios acreanos. In: CAVALHEIRO, J.; LUDWIG, C. R.; LANES, E. J. (org.). Lingu(agem), ensino e formação docente. Manaus: Editora UEA, 2019a.

SOUSA, A. M de.; QUADROS, R. M. O Web Software Toponímia em Libras: pesquisa e ensino. In: SOUZA, Alexandre Melo de; GARCIA, Rosane; SANTOS, Tatiane Castro dos (org.). Perspectivas para o ensino de línguas 3. São Carlos (SP): Pedro \& João Editores, 2019b. Disponível em:

https://ebookspedroejoaoeditores.wordpress.com/2019/09/13/perspectivas-para-oensino-de-linguas-volume-3/. Acesso em: 10 out. 2020.

SOUZA, K. M. de; NOVODVORSKI, A. Toponímia em Libras: Análise da origem motivacional em sinais toponímicos do Estado de Goiás. Revista do Sell, [S.l.], v. 9, n. 1, p. 36-54, 2020. DOI https://doi.org/10.18554/rs.v9i1.4106

URBANSKI, I. R. W.; XAVIER, A. N.; FERREIRA, D. Topônimos na Libras: análise preliminar de sinais que nomeiam cidades do estado do Paraná. In: XXI SEMANA DE LETRAS - UFPR - Universidade Federal do Paraná, Volume II, Curitiba, Trabalhos completos [...]. Universidade Federal do Paraná, 2019. p. 64-73. 


\section{APÊNDICE - LINKS DO YOUTUBE}

\begin{tabular}{|c|c|c|}
\hline Região & Estado & Link \\
\hline \multirow[t]{2}{*}{ Norte } & $\mathrm{AC}$ & $\begin{array}{l}\text { https://www.youtube.com/watch?v=C2YAyUQwUCY } \\
\text { https://www.youtube.com/watch?v=sgehwhmx8n8 }\end{array}$ \\
\hline & PA & https://www.youtube.com/watch?v=05JqJtCnQfY \\
\hline \multirow[t]{4}{*}{ Nordeste } & CE & https://redesurdosce.ufc.br/municipios-do-ceara/ \\
\hline & PE & $\begin{array}{l}\text { https://www.youtube.com/watch?v=Vn7Yzt74v8g } \\
\text { https://www.youtube.com/watch?v=UV3nQTY-wig }\end{array}$ \\
\hline & MA & https://www.youtube.com/channel/UCJOSYwumI01vxsBbkg_p_mA \\
\hline & RN & https://www.youtube.com/watch?v=GxkkW9QiynI \\
\hline \multirow[t]{3}{*}{$\begin{array}{l}\text { Centro- } \\
\text { Oeste }\end{array}$} & DF & $\begin{array}{l}\text { https://www.youtube.com/watch?v=Zrf2yKnnAAk } \\
\text { https://www.youtube.com/watch?v=165bk1M_N58 } \\
\text { https://www.youtube.com/watch?v=vQCKlkaH81A }\end{array}$ \\
\hline & MT & https://www.youtube.com/watch?v=sqE_HW5Qp98 \\
\hline & MS & $\begin{array}{l}\text { https://www.youtube.com/watch?v=u6hPV7GfphA } \\
\text { https://www.youtube.com/watch?v=WDVrgEgCKFc }\end{array}$ \\
\hline \multirow[t]{3}{*}{ Sudeste } & MG & $\begin{array}{l}\text { https://www.youtube.com/watch?v=hs9svNvHfPQ } \\
\text { https://www.youtube.com/watch?v=ee19aeaFqdU } \\
\text { https://www.youtube.com/channel/UCBMCoXdeIq_NP6ihSh0RI_w } \\
\text { /search?query=cidade }\end{array}$ \\
\hline & SP & $\begin{array}{l}\text { https://www.youtube.com/watch?v=4SeSAn13ZP0 } \\
\text { https://www.youtube.com/watch?v=b-XJE_Ko9Ys } \\
\text { https://www.youtube.com/watch?v=-mJJhwhuWJU } \\
\text { https://www.youtube.com/channel/UCYa209a1Yf2- } \\
\text { 1pmnG_rqyTw/search?query=cidade }\end{array}$ \\
\hline & ES & https://www.youtube.com/watch?v=X6uV-TxgkqI \\
\hline \multirow[t]{3}{*}{ Sul } & PR & $\begin{array}{l}\text { https://www.youtube.com/watch?v=lLYhPg_jNIQ } \\
\text { https://youtu.be/EY8CRSi1HAU }\end{array}$ \\
\hline & SC & https://www.youtube.com/watch?v=iYiwrWCDW1o \\
\hline & RS & $\begin{array}{l}\text { https://www.youtube.com/watch?v=jKquphgkeVk } \\
\text { https://www.youtube.com/watch?v=UIsdx8s-pHo }\end{array}$ \\
\hline
\end{tabular}

